Supporting Information for

\title{
On the role of dioxane in the synthesis of In-derived MOFs
}

Caleb J. Tatebe, ${ }^{a}$ Saidah Yusuf, ${ }^{\mathrm{a}}$ Michael K. Bellas, ${ }^{\mathrm{a}}$ Matthias Zeller, ${ }^{\mathrm{b}}$ Christopher Arntsen, ${ }^{\mathrm{a}}$ Douglas T. Gennaa,*

a) Department of Chemistry, Youngstown State University, Youngstown, OH 44555

b) Department of Chemistry, Purdue University, West Lafayette, IN 47907 
Table of Contents

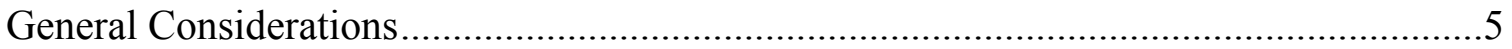

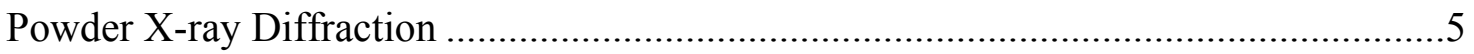

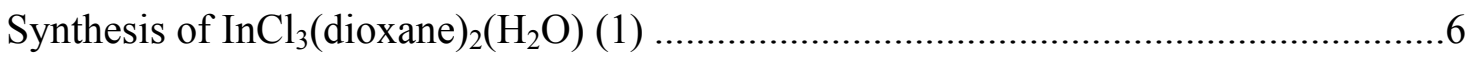

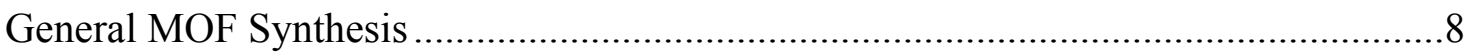

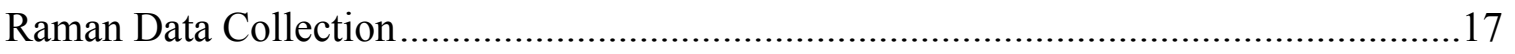

Molecular Dynamics Computations ......................................................................... 21

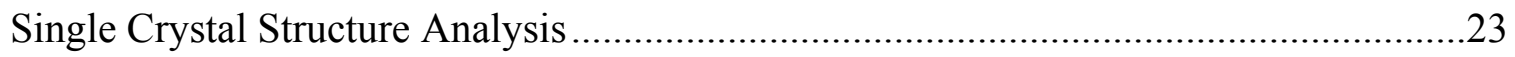

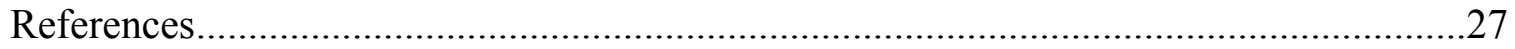

\section{Table of Figures and Tables}

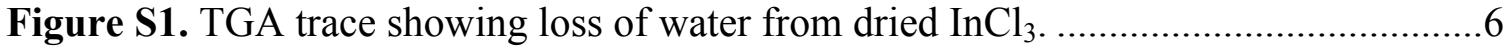

Figure S2. X-ray diffraction pattern for $\mathrm{InCl}_{3}(\text { dioxane })_{2}\left(\mathrm{H}_{2} \mathrm{O}\right)(\mathbf{1})$ with experimental (red)

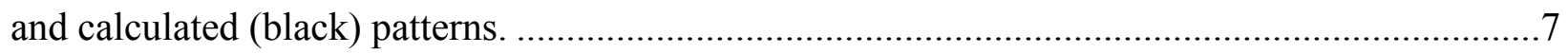

Figure S3. Solid-state Raman spectra of $\operatorname{InCl}_{3}\left(\mathrm{H}_{2} \mathrm{O}\right)$ (black) and 1 (red) shown from 180$3200 \mathrm{~cm}^{-1}$. An inset image displays spectra between $250-550 \mathrm{~cm}^{-1}$.

Figure S4. X-ray diffraction patterns for MIL-68 prepared with different reaction conditions. All depicted routes were at $120^{\circ} \mathrm{C}$. .8

Figure S5. X-ray diffraction patterns for MIL-68 prepared from different synthetic routes. All depicted experiments were carried out at $100^{\circ} \mathrm{C}$.

Figure S6. X-ray diffraction patterns for QMOF-2 prepared from different routes. All depicted routes were at $120^{\circ} \mathrm{C}$

Figure S7. X-ray diffraction patterns for QMOF-2 prepared from different synthetic routes. All experiments depicted were carried out at $100{ }^{\circ} \mathrm{C}$. 10

Figure S8. X-ray diffraction patterns for ATF-1 prepared from different routes. All experiments were carried out at $120^{\circ} \mathrm{C}$.

Figure S9. X-ray diffraction patterns of ATF-1 prepared from different synthetic routes. All depicted experiments were carried out at $100{ }^{\circ} \mathrm{C}$. 
Figure S10. X-ray diffraction patterns of ZJU-28 prepared from different synthetic routes. All depicted experiments were carried out at $120^{\circ} \mathrm{C}$. .11

Figure S11. X-ray diffraction patterns of ZJU-28 prepared from different synthetic routes. All depicted experiments were carried out at $100^{\circ} \mathrm{C}$. .12

Figure S12. X-ray diffraction patterns from reactions using DMF/toluene attempting to prepare MIL-68. Samples from reactions at $100{ }^{\circ} \mathrm{C}$ (blue) and $120^{\circ} \mathrm{C}$ (red). .13

Figure S13. X-ray diffraction patterns using DMF/toluene attempting to prepare QMOF2. Samples from reactions at $100 \mathrm{C}$ (blue) and $120 \mathrm{C}$ (red). .13

Figure S14. X-ray diffraction patterns from reactions using DMF/THP attempting to prepare MIL-68. Samples from reactions at $100{ }^{\circ} \mathrm{C}$ (blue) and $120^{\circ} \mathrm{C}$ (red). .14

Figure S15. X-ray diffraction patterns from reactions using DMF/THP attempting to prepare QMOF-2. Samples from reactions at $100{ }^{\circ} \mathrm{C}$ (blue) and $120^{\circ} \mathrm{C}$ (red). .15

Figure S16. X-ray powder diffraction patterns of MIL-68 using different mixed solvent systems. Both traces were from reactions carried out at $120^{\circ} \mathrm{C}$. .15

Figure S17. X-ray powder diffraction patterns of QMOF-2 using different mixed solvent systems. Both traces were from reactions carried out at $120^{\circ} \mathrm{C}$. 16

Figure S18. X-ray powder diffraction patters of ATF-1 using different mixed solvent systems. Both traces were from reactions carried out at $120^{\circ} \mathrm{C}$. .16

Figure S19. X-ray powder diffraction pattern of ZJU-28 in DMF/dioxane. Reaction carried out at $120^{\circ} \mathrm{C}$. .17

Figure S20. In-house Raman "oven"-like environment. Shown with closed box (left), use of sand bath for heating (middle), and with the metal covering in place (right). 17

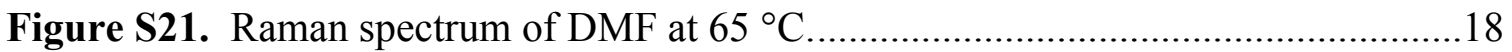

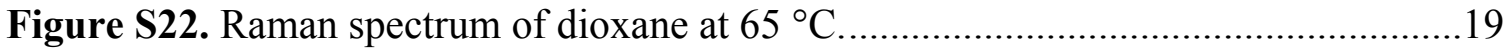

Figure S23. 2-Dimensional contour plot of Raman data of $\mathrm{InCl}_{3}\left(\mathrm{OH}_{2}\right)$ in dioxane heated at $65^{\circ} \mathrm{C}$ for 22 hours and then cooled to room temperature. .19

Figure S24. Radial distribution function (RDF) of formate oxygen to solvent. .21

Table S1. Time of initial nucleation as a function of solvent and indium source. Time reported as hours. All values are an average of at least three runs, standard error in parenthesis. 12 
Table S2. Summary of computational data ( $\omega$ B97X-D functional and 6-316G basis set) for the disproportionation of octahedral $\mathrm{InCl}_{3}(\text { trans-solv })_{2}\left(\mathrm{OH}_{2}\right)$.......................................20

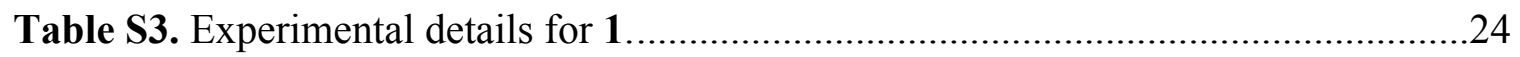




\section{General Considerations}

Terephthalic acid (Sigma Aldrich), and 2,5-thiopehenedicarboxylic acid (Alfa Aesar) were purchased from commercial sources and used as received. $\mathrm{InCl}_{3}$ was received as a generous gift from the University of Toledo - Department of Chemistry, which was dried overnight at room temperature under reduced pressure and stored in a dry box prior to use. TGA data were collected on a TA Instruments TGA Q50 from $50{ }^{\circ} \mathrm{C}$ to $600{ }^{\circ} \mathrm{C}$ at a rate of $10{ }^{\circ} \mathrm{C}$ per minute. Raman spectroscopy was recorded using a Kaiser Optical Systems RXN1-785 (wavelength $=785 \mathrm{~nm}$ ) spectrometer, RamanRxn Probe attachment (2011683-005-X2 311819) housed in a custom-built oven (Figure S20) for in situ study.

Computations were performed using the Spartan '18 software package. DFT calculations were conducted using the $\omega \mathrm{B} 97 \mathrm{X}-\mathrm{D} 44,45$ functional and 6-316G* basis set for all non-In atoms while the LANL2DZ-SV basis set was used for In. Solution phase calculations were performed using an implicit solvent model at 293.15 K. Output files and optimized coordinates are available upon request.

\section{Powder X-ray Diffraction}

Powder XRD patterns of small samples were collected on a Bruker AXS X8 Prospector CCD single crystal diffractometer using the "pilot" plugin for collection of multicrystalline XRD patterns. The instrument is equipped with a copper $\mathrm{I} \mu \mathrm{S}$ microsource with a laterally graded multilayer (Goebel) mirror for monochromatization $(\lambda=1.54178 \AA$, beam size $0.1-0.2 \mathrm{~mm})$ and an ApexII CCD area detector. Powder samples were thoroughly ground to assure a representative number of crystallites to be present in the X-ray beam. Powder samples were mixed with small amounts of mineral oil and mounted onto a $0.4 \mathrm{~mm}$ diameter Mitegen micromesh mount for data collection. Samples were centered in the beam using the instrument's mounting microscope video camera. Data were collected in an emulated theta-2theta setup using the Apex $2^{1}$ software package of Bruker AXS. The sample mount was aligned horizontally $\left(\mathrm{Chi}=0^{\circ}\right)$ and theta angles were set to eight different angles between 12 and $96^{\circ}$ to cover a range equivalent to a 0 to $110^{\circ}$ range of a powder X-ray diffractometer operated in Debye Scherrer mode (omega angles of each run were set to half the theta values). Samples were rotated around the mount's spindle axis during measurement $\left(360^{\circ}\right.$ rotation around phi), typical exposure times were 30 seconds per frame 
collected. The eight individual patterns taken were corrected for unequal sample to detector surface distance ("unwarped") and were combined into one continuous pattern using the "pilot plugin" software embedded in the Apex2 software package. Data were integrated over 2theta, converted in powder XRD patterns in Bruker "raw" format and were further processed with standard powder XRD software packages.

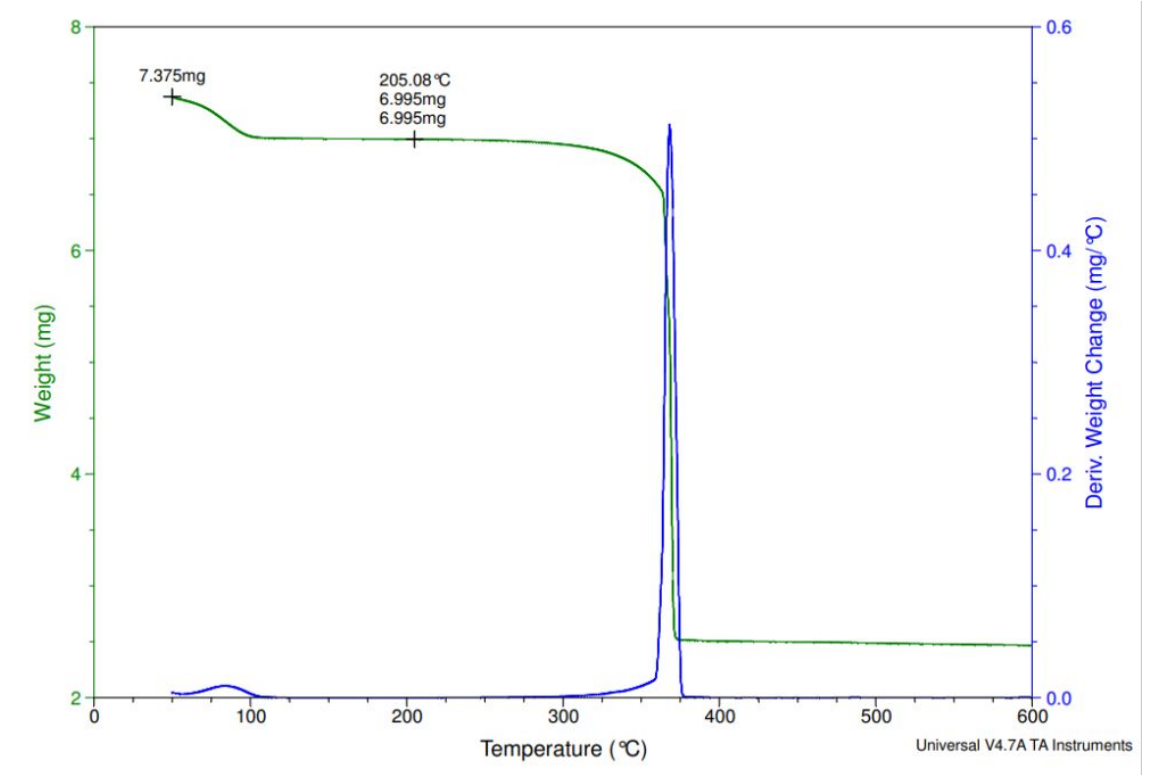

Figure S1. TGA trace showing loss of water from dried $\mathrm{InCl}_{3}$.

\section{Synthesis of $\operatorname{InCl}_{3}(\text { dioxane })_{2}\left(\mathrm{H}_{2} \mathrm{O}\right)(1)$}

A $20 \mathrm{~mL}$ scintillation vial was charged with $\mathrm{InCl}_{3}\left(\mathrm{H}_{2} \mathrm{O}\right)(0.200 \mathrm{~g}, 0.836 \mathrm{mmol})$ in $10 \mathrm{~mL}$ dioxane. The suspension was heated at $90{ }^{\circ} \mathrm{C}$ at which time the $\operatorname{InCl}_{3}\left(\mathrm{H}_{2} \mathrm{O}\right)$ fully dissolved. The solution was kept at $90{ }^{\circ} \mathrm{C}$ for $18 \mathrm{hr}$. The solution was then removed from the heat and allowed to cool to room temperature, upon reaching room temperature colorless block-like crystals formed $(0.308 \mathrm{~g}$, $0.741 \mathrm{mmol}, 89 \%$ yield). These crystals were stored as a suspension in dioxane prior to use at which time excess dioxane was decanted and the crystals were allowed to air-dry for 20 minutes.

Note: upon drying, compound 1 will undergo hydrolysis if exposed to atmospheric conditions for more than 2 hours. 


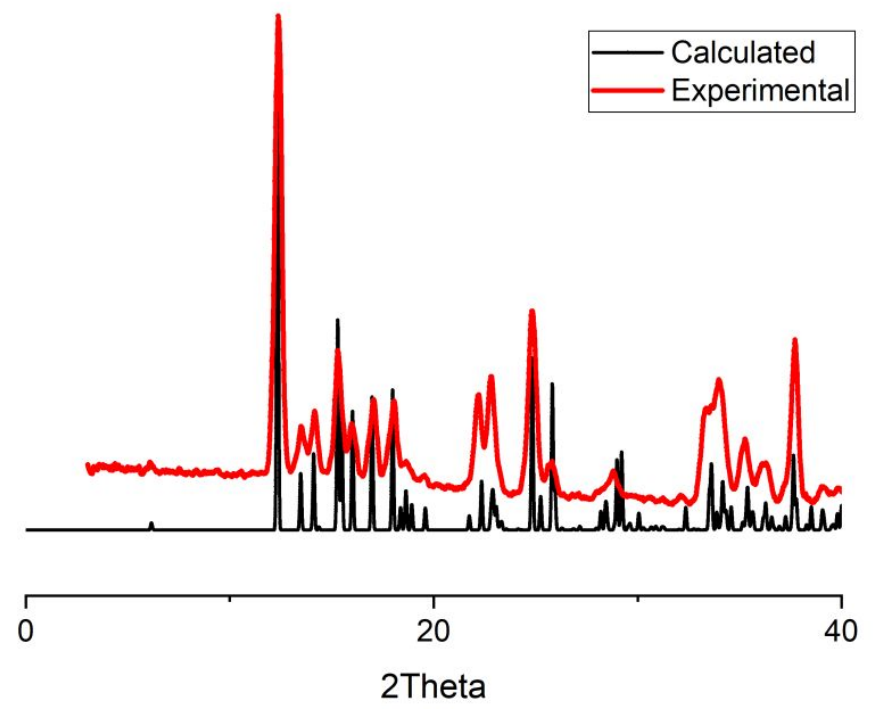

Figure S2. X-ray diffraction pattern for $\mathrm{InCl}_{3}(\text { dioxane })_{2}\left(\mathrm{H}_{2} \mathrm{O}\right)(\mathbf{1})$ with experimental (red) and calculated (black) patterns.

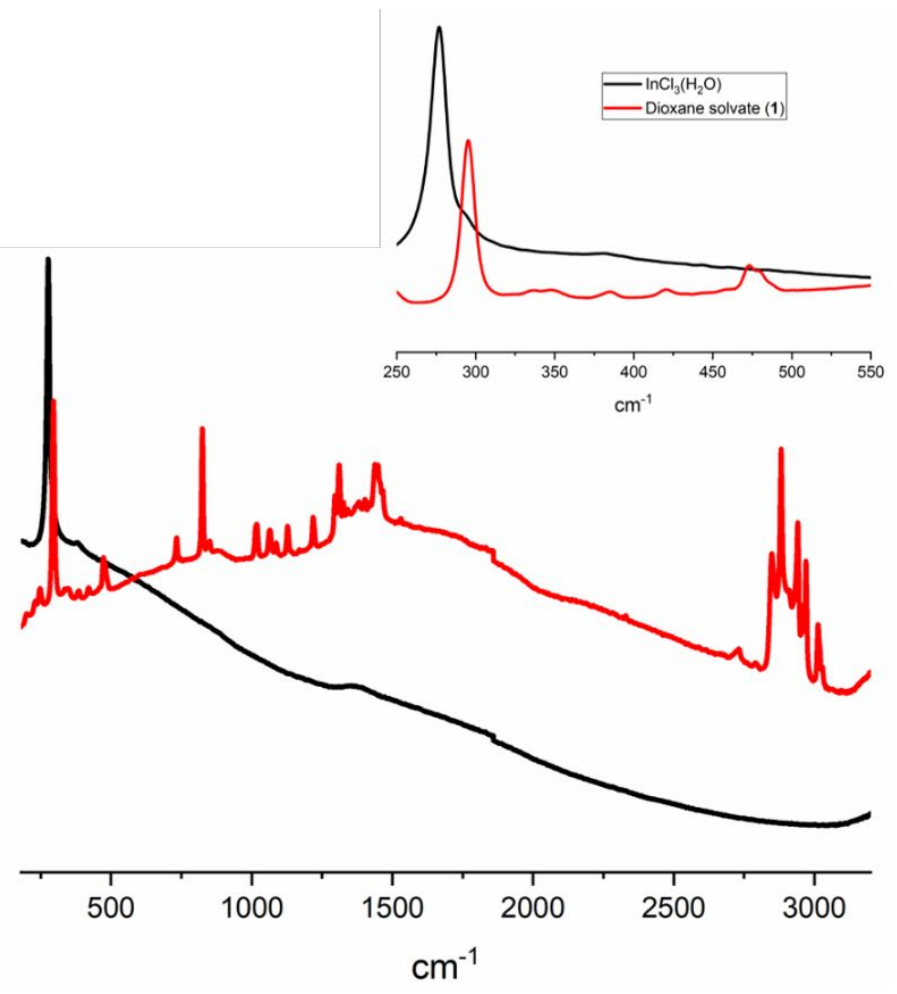

Figure S3. Solid-state Raman spectra of $\mathrm{InCl}_{3}\left(\mathrm{H}_{2} \mathrm{O}\right)$ (black) and 1 (red) shown from 180-3200 $\mathrm{cm}^{-}$ 1. An inset image displays spectra between $250-550 \mathrm{~cm}^{-1}$. 


\section{General MOF Synthesis}

A $50 \mathrm{~mL}$ Erlenmeyer flask was charged with [In] $\left(\left[\mathrm{In}=\mathrm{InCl}_{3}\left(\mathrm{H}_{2} \mathrm{O}\right)\right.\right.$ or $\left.\operatorname{InCl}_{3}(\text { dioxane })_{2}\left(\mathrm{H}_{2} \mathrm{O}\right)(\mathbf{1})\right)$ (1.0 mmol) in $12 \mathrm{~mL}$ solvent (DMF, DMF:solvent 3:2 (bv) (solvent = dioxane, toluene, tetrahydropyran). To this solution, ligand (MIL-68: terephthalic acid, $0.5 \mathrm{mmol}$; QMOF-2, terephthalic acid, $2.0 \mathrm{mmol}$; ATF-1, 2,5-thiophene dicarboxylic acid $0.9 \mathrm{mmol}$; ZJU-28, 4,4',4"benzene-1,3,5-triyltribenzoic acid $\left.\left(\mathrm{H}_{3} \mathrm{BTB}\right), 0.45 \mathrm{mmol}\right)$ was added and the flask was sonicated for 15 minutes (NOTE - for the synthesis of ZJU-28, 1 mL distilled $\mathrm{H}_{2} \mathrm{O}$ was also added, to aid in the dissolution of $\mathrm{H}_{3} \mathrm{BTB}$ ). Following sonication, the solution was filtered [via GE syringe filter] into $20 \mathrm{~mL}$ scintillation vials in $6 \mathrm{~mL}$ portions. The vials were placed in an oven $\left(100{ }^{\circ} \mathrm{C}\right.$ or 120 ${ }^{\circ} \mathrm{C}$ ) and monitored regularly. Upon observation of any viable amount of solid for pXRD analysis, the vial was removed and the solids were washed with fresh DMF $(3 \times 5 \mathrm{~mL})$.

Samples were compared with the calculated powder X-ray diffraction patterns from their literature values [ATF-1, ${ }^{2}$ MIL-68, ${ }^{3}$ QMOF-2, ${ }^{4}$ ZJU-285 $]$ for structure confirmation and purity.

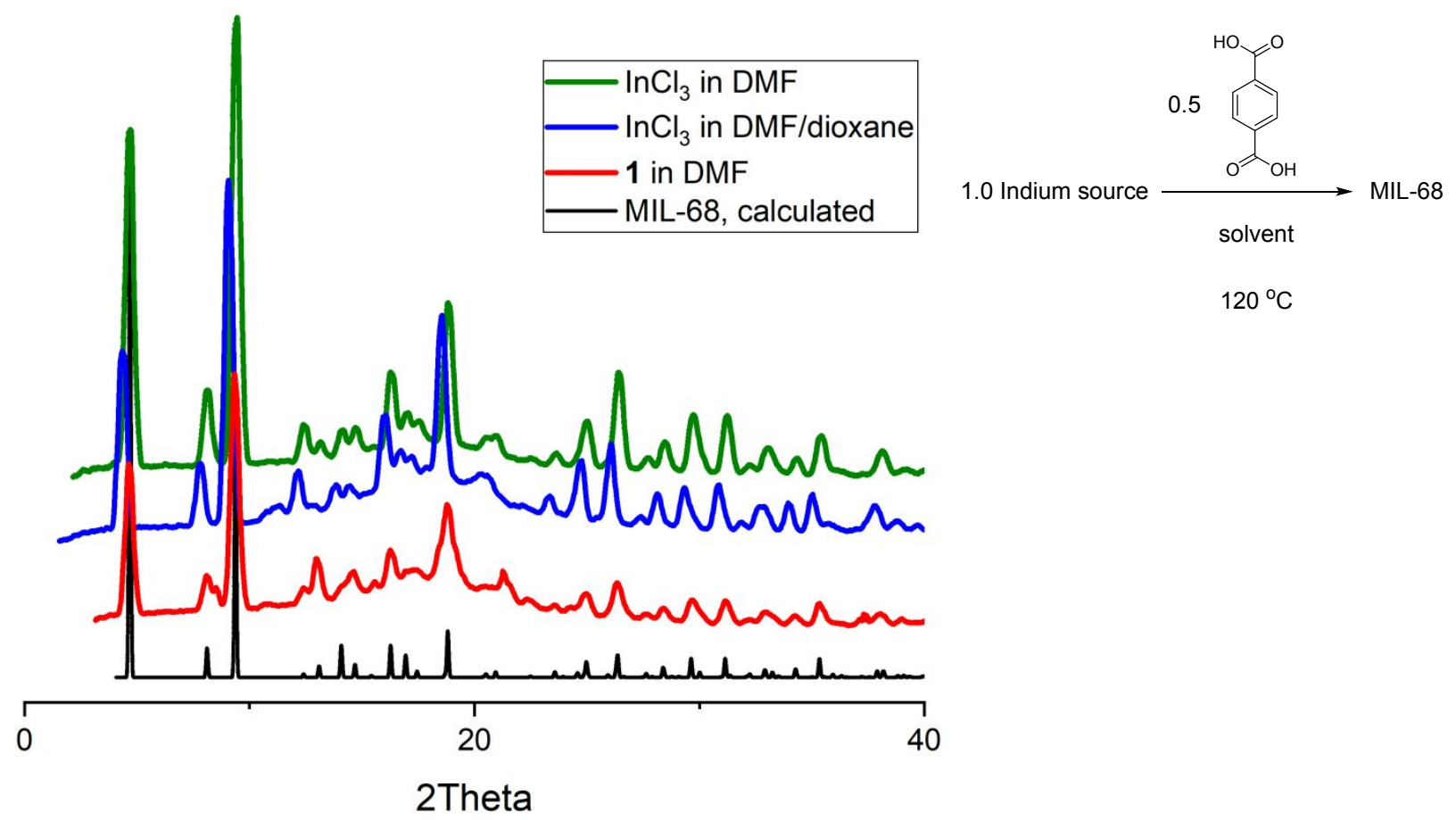

Figure S4. X-ray diffraction patterns for MIL-68 prepared with different reaction conditions. All depicted routes were at $120^{\circ} \mathrm{C}$. 


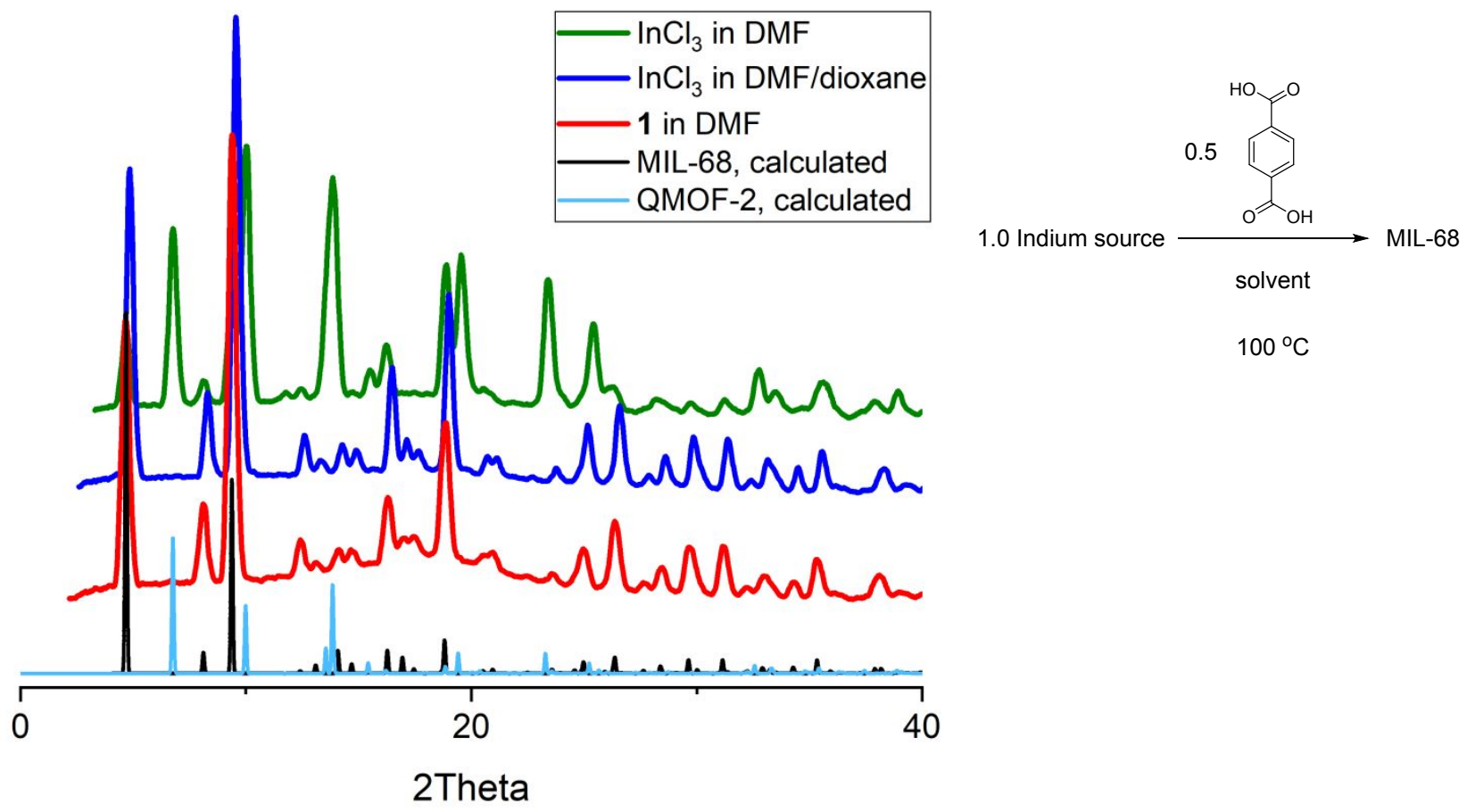

Figure S5. X-ray diffraction patterns for MIL-68 prepared from different synthetic routes. All depicted experiments were carried out at $100{ }^{\circ} \mathrm{C}$.

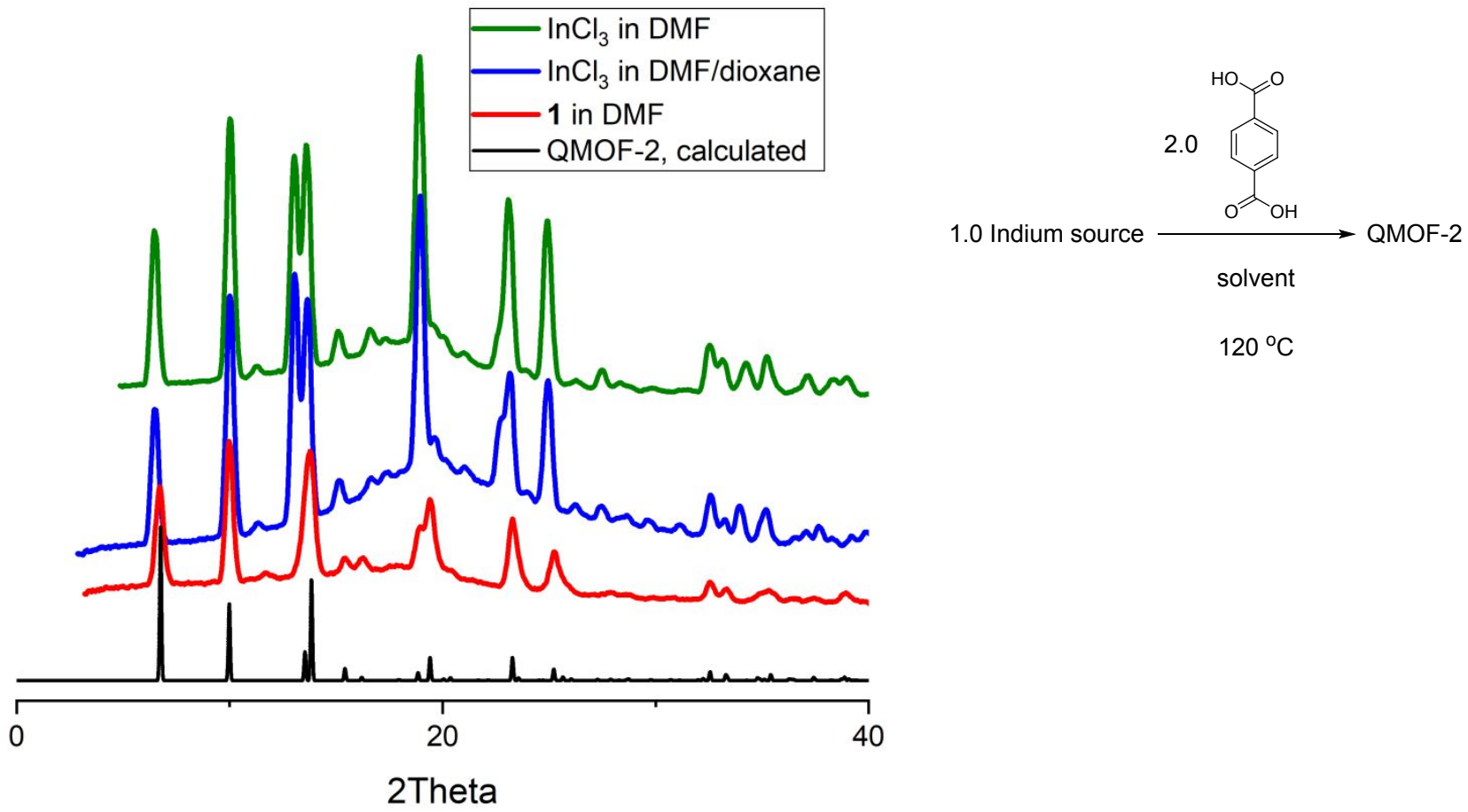

Figure S6. X-ray diffraction patterns for QMOF-2 prepared from different routes. All depicted routes were at $120{ }^{\circ} \mathrm{C}$. 


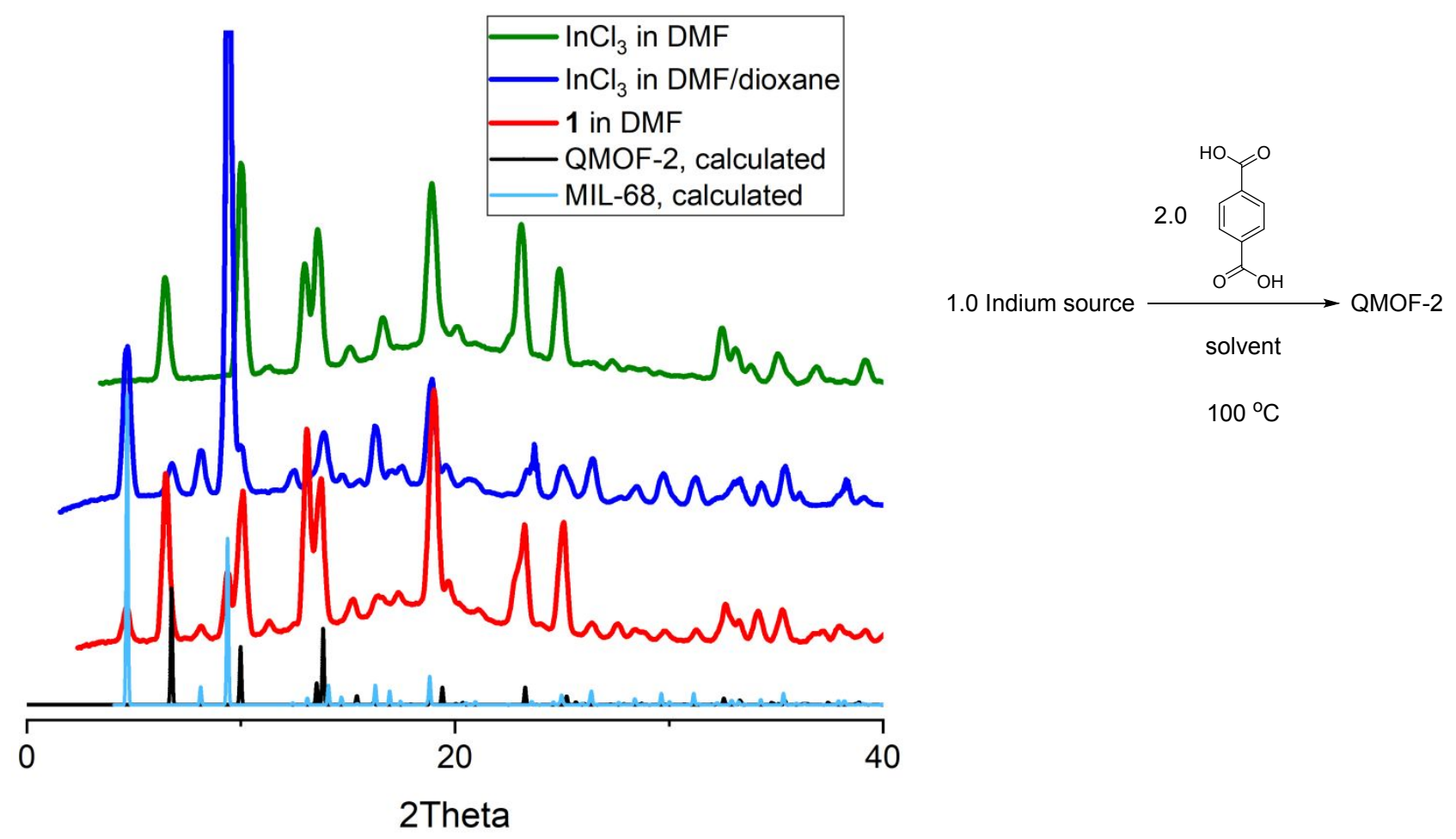

Figure S7. X-ray diffraction patterns for QMOF-2 prepared from different synthetic routes. All experiments depicted were carried out at $100{ }^{\circ} \mathrm{C}$.

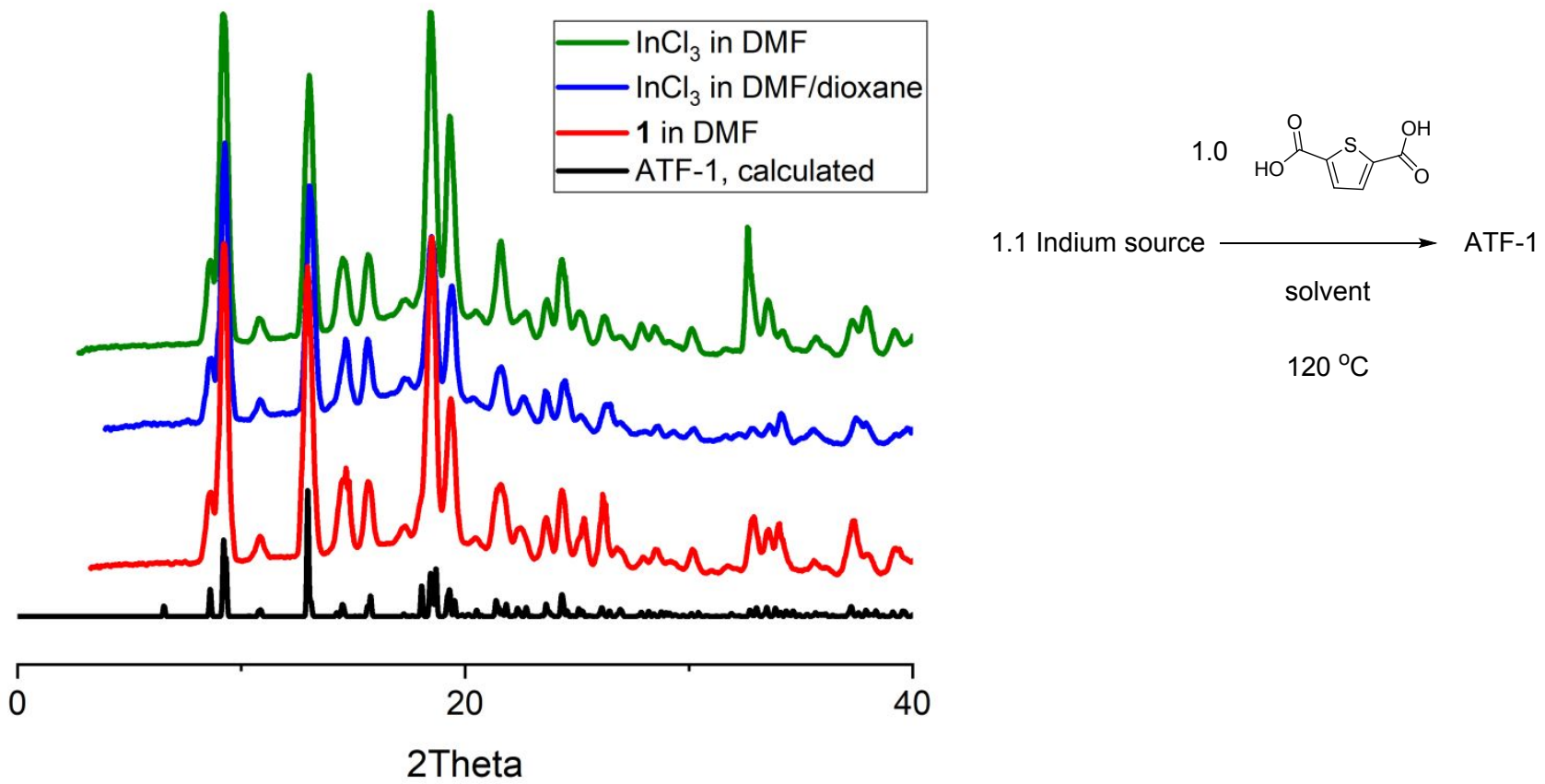

Figure S8. X-ray diffraction patterns for ATF-1 prepared from different routes. All experiments were carried out at $120^{\circ} \mathrm{C}$. 


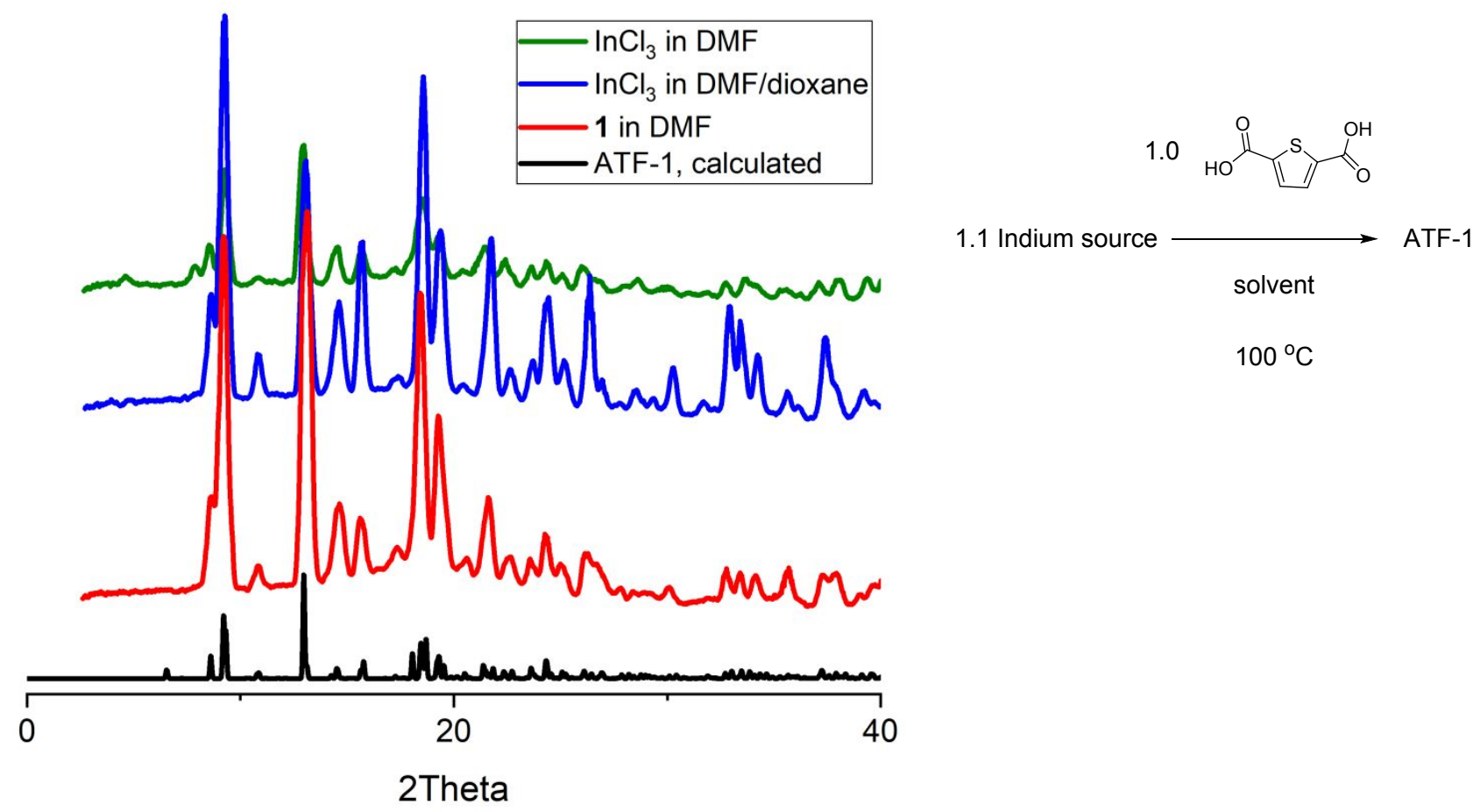

Figure S9. X-ray diffraction patterns of ATF-1 prepared from different synthetic routes. All depicted experiments were carried out at $100{ }^{\circ} \mathrm{C}$.

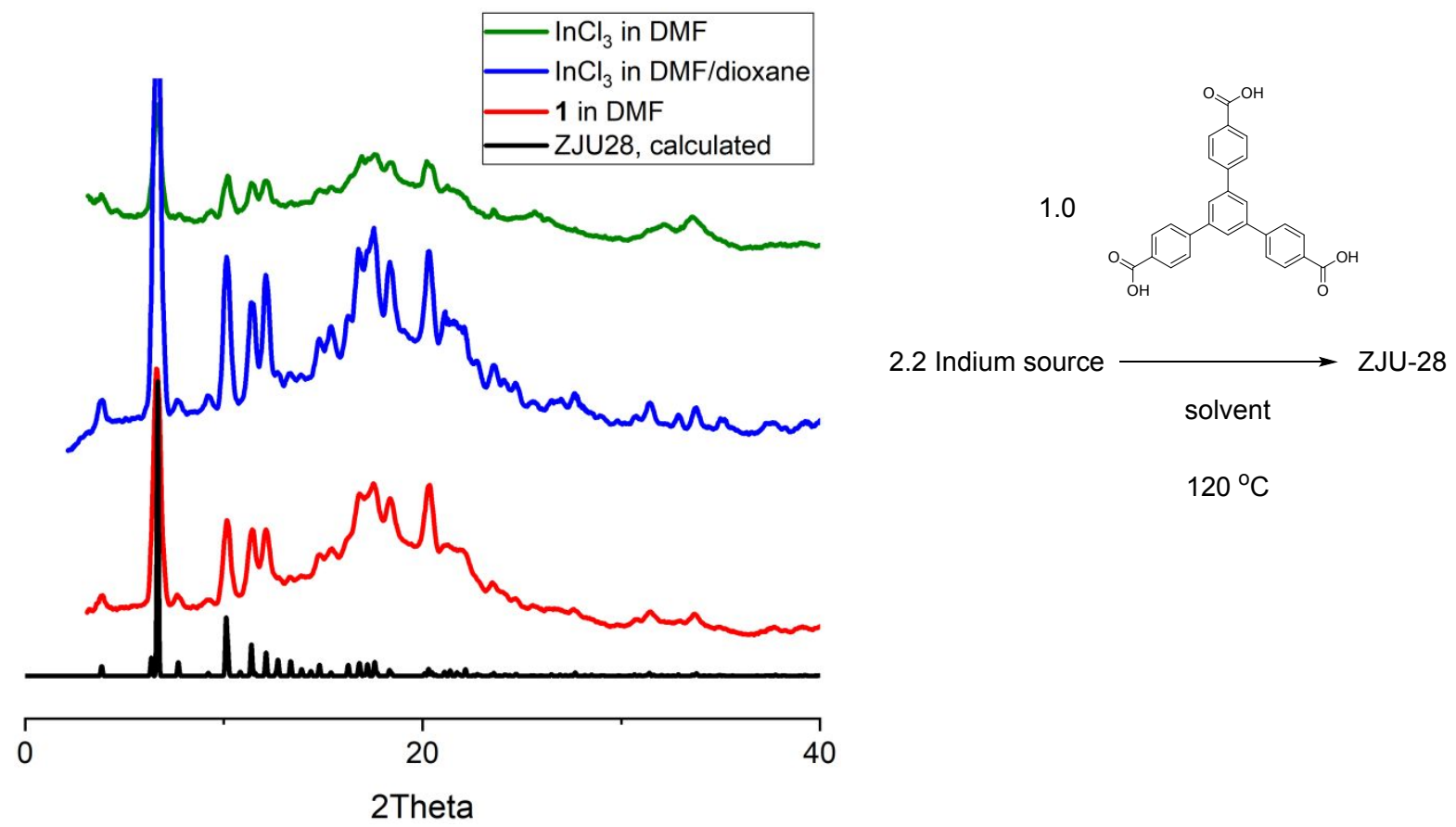

Figure S10. X-ray diffraction patterns of ZJU-28 prepared from different synthetic routes. All depicted experiments were carried out at $120^{\circ} \mathrm{C}$. 


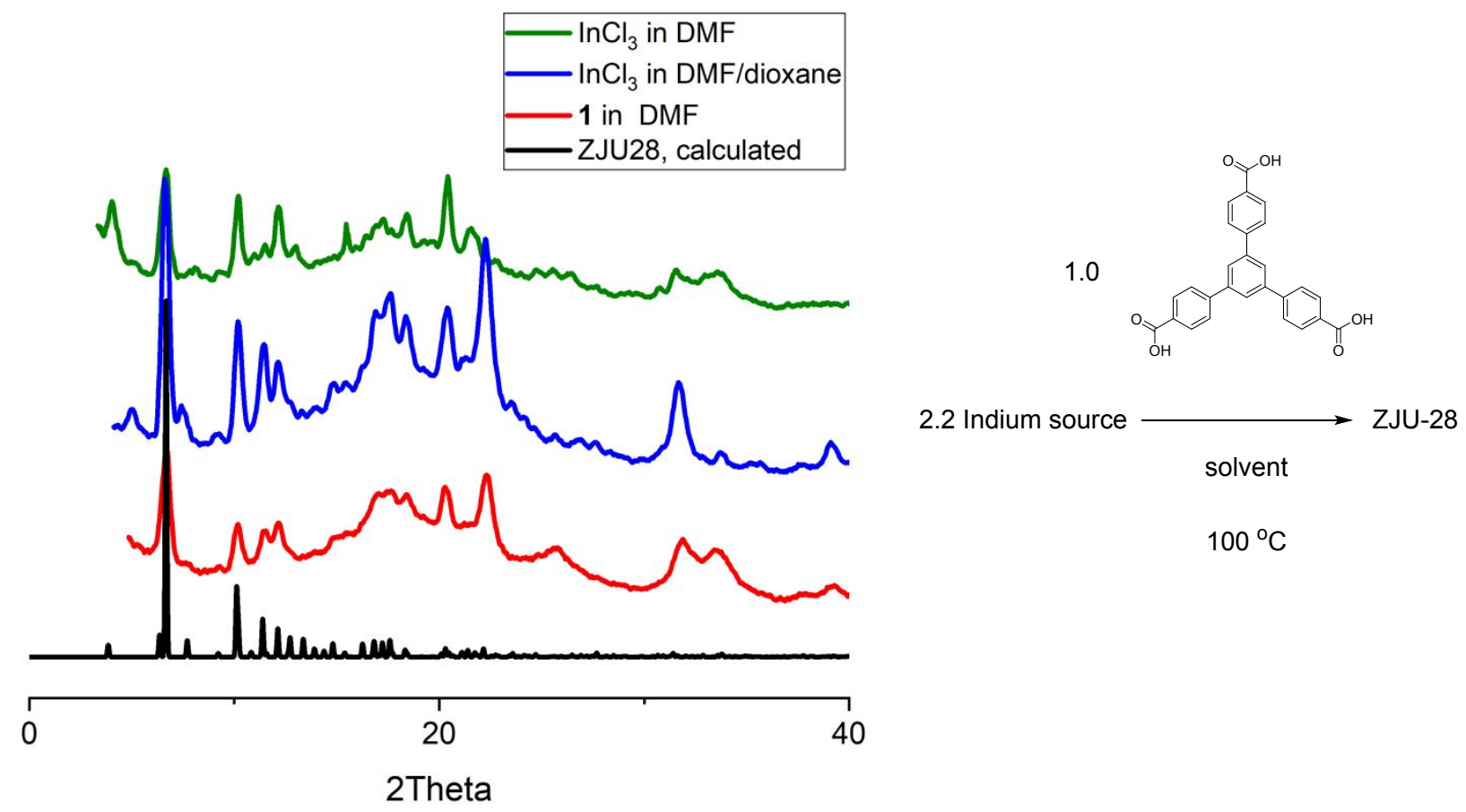

Figure S11. X-ray diffraction patterns of ZJU-28 prepared from different synthetic routes. All depicted experiments were carried out at $100{ }^{\circ} \mathrm{C}$.

Table S1. Time of initial nucleation as a function of solvent and indium source. Time reported as hours. All values are an average of at least three runs, standard error in parenthesis.

\begin{tabular}{|c|c|c|c|c|c|c|}
\hline & $\begin{array}{c}\mathrm{InCl}_{3} \text { in } \\
\mathrm{DMF} / \text { dioxane } \\
\left(100{ }^{\circ} \mathrm{C}\right)\end{array}$ & $\begin{array}{c}\mathbf{1} \text { in } \\
\mathrm{DMF} \\
\left(100{ }^{\circ} \mathrm{C}\right)\end{array}$ & $\begin{array}{c}\mathrm{InCl}_{3} \text { in } \\
\mathrm{DMF} / \mathrm{THP} \\
\left(120^{\circ} \mathrm{C}\right)\end{array}$ & $\begin{array}{c}\mathrm{InCl}_{3} \text { in } \\
\mathrm{DMF} / \text { toluene } \\
\left(120^{\circ} \mathrm{C}\right)\end{array}$ & $\begin{array}{c}\mathbf{1} \text { in } \\
\mathrm{DMF} / \text { dioxane } \\
\left(120{ }^{\circ} \mathrm{C}\right)\end{array}$ & $\begin{array}{c}\mathbf{1} \text { in } \\
\text { DMF/toluene } \\
\left(120^{\circ} \mathrm{C}\right)\end{array}$ \\
\hline ZJU-28 & $33(5)$ & $34(16)$ & & $17(3)$ & -- \\
\hline ATF-1 & $20(1)$ & $19(2)$ & & $18(1)$ & $20(4)$ \\
\hline QMOF-2 & $24(0.5)$ & $23(7)$ & $36(4)$ & $19(2)$ & $18(2)$ & $20(4)$ \\
\hline MIL-68 & $26(6)$ & $18(11)$ & $38(8)$ & $26(2)$ & $18(3)$ & $15(1)$ \\
\hline
\end{tabular}




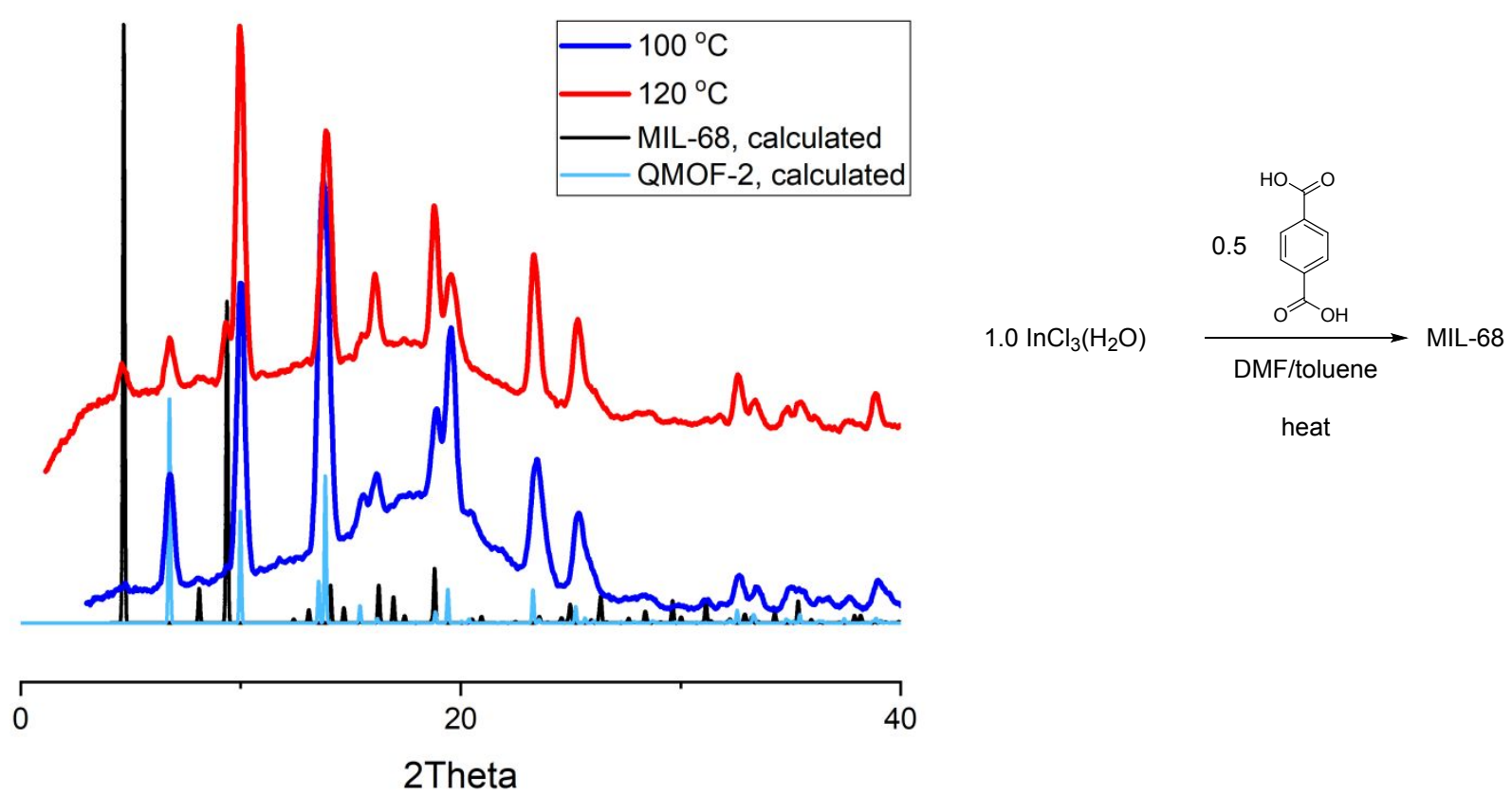

Figure S12. X-ray diffraction patterns from reactions using DMF/toluene attempting to prepare MIL-68. Samples from reactions at $100{ }^{\circ} \mathrm{C}$ (blue) and $120^{\circ} \mathrm{C}$ (red).

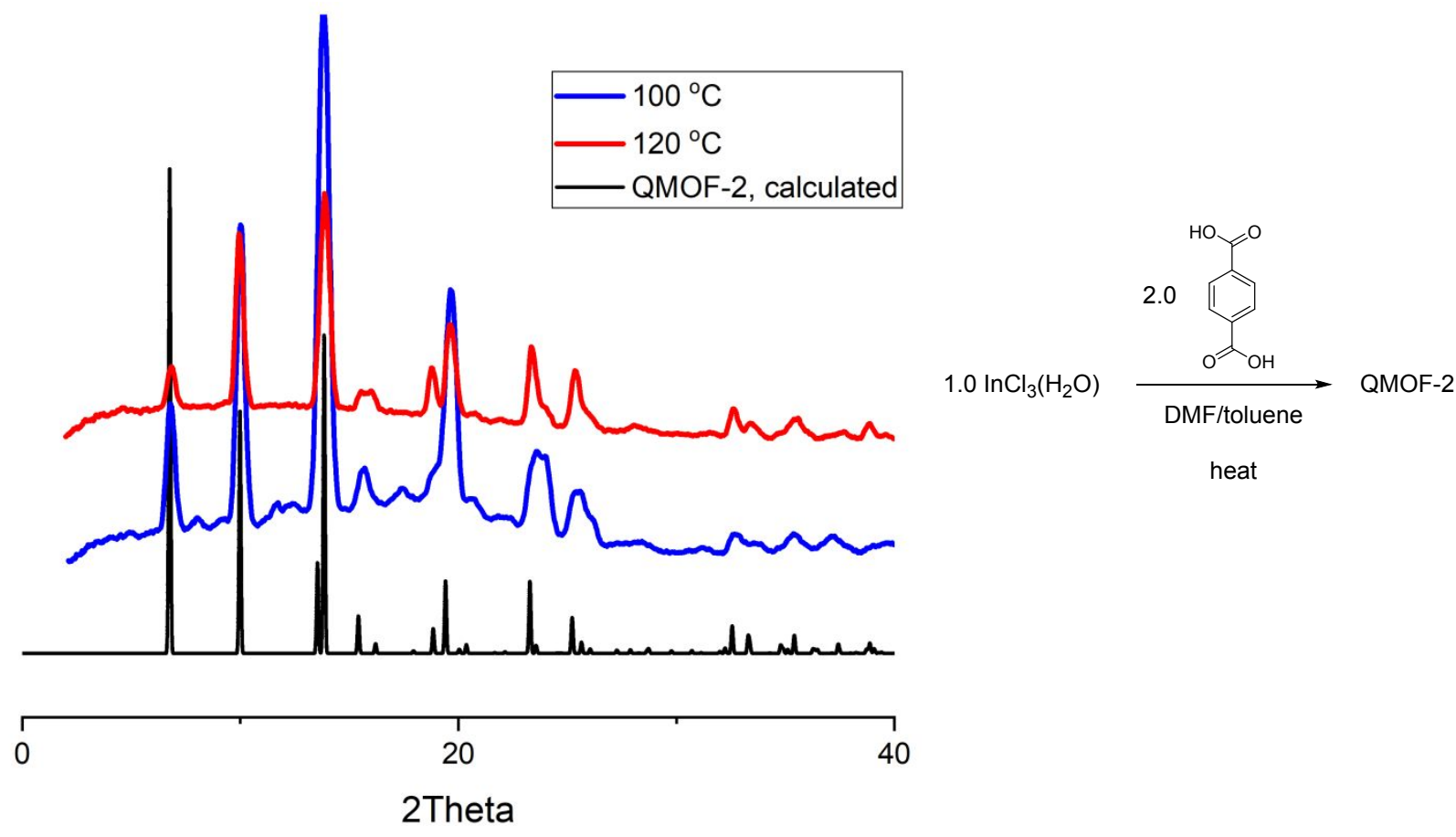

Figure S13. X-ray diffraction patterns using DMF/toluene attempting to prepare QMOF-2. Samples from reactions at $100 \mathrm{C}$ (blue) and $120 \mathrm{C}$ (red). 


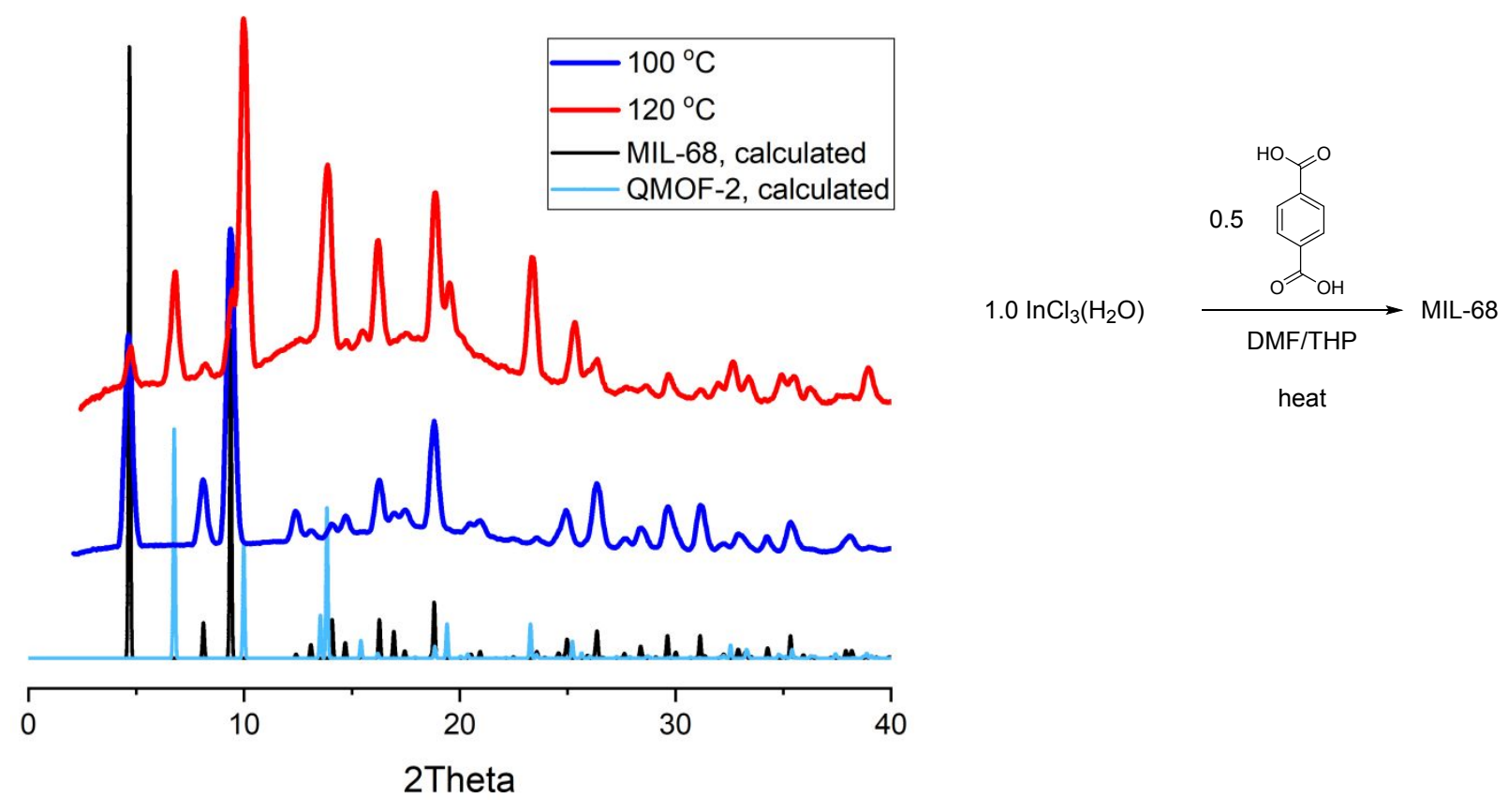

Figure S14. X-ray diffraction patterns from reactions using DMF/THP attempting to prepare MIL68. Samples from reactions at $100{ }^{\circ} \mathrm{C}$ (blue) and $120^{\circ} \mathrm{C}$ (red). 


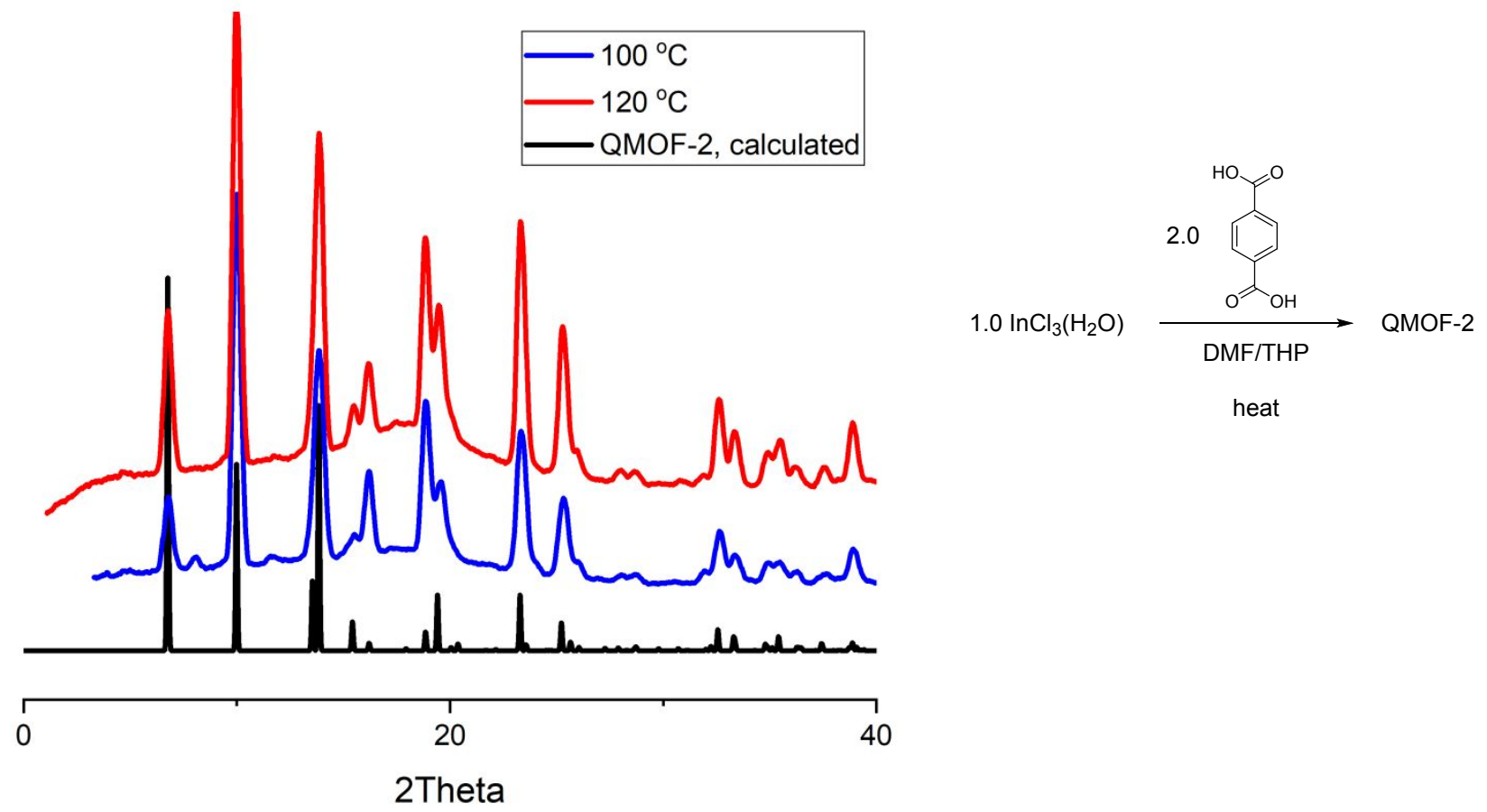

Figure S15. X-ray diffraction patterns from reactions using DMF/THP attempting to prepare QMOF-2. Samples from reactions at $100^{\circ} \mathrm{C}$ (blue) and $120^{\circ} \mathrm{C}$ (red).

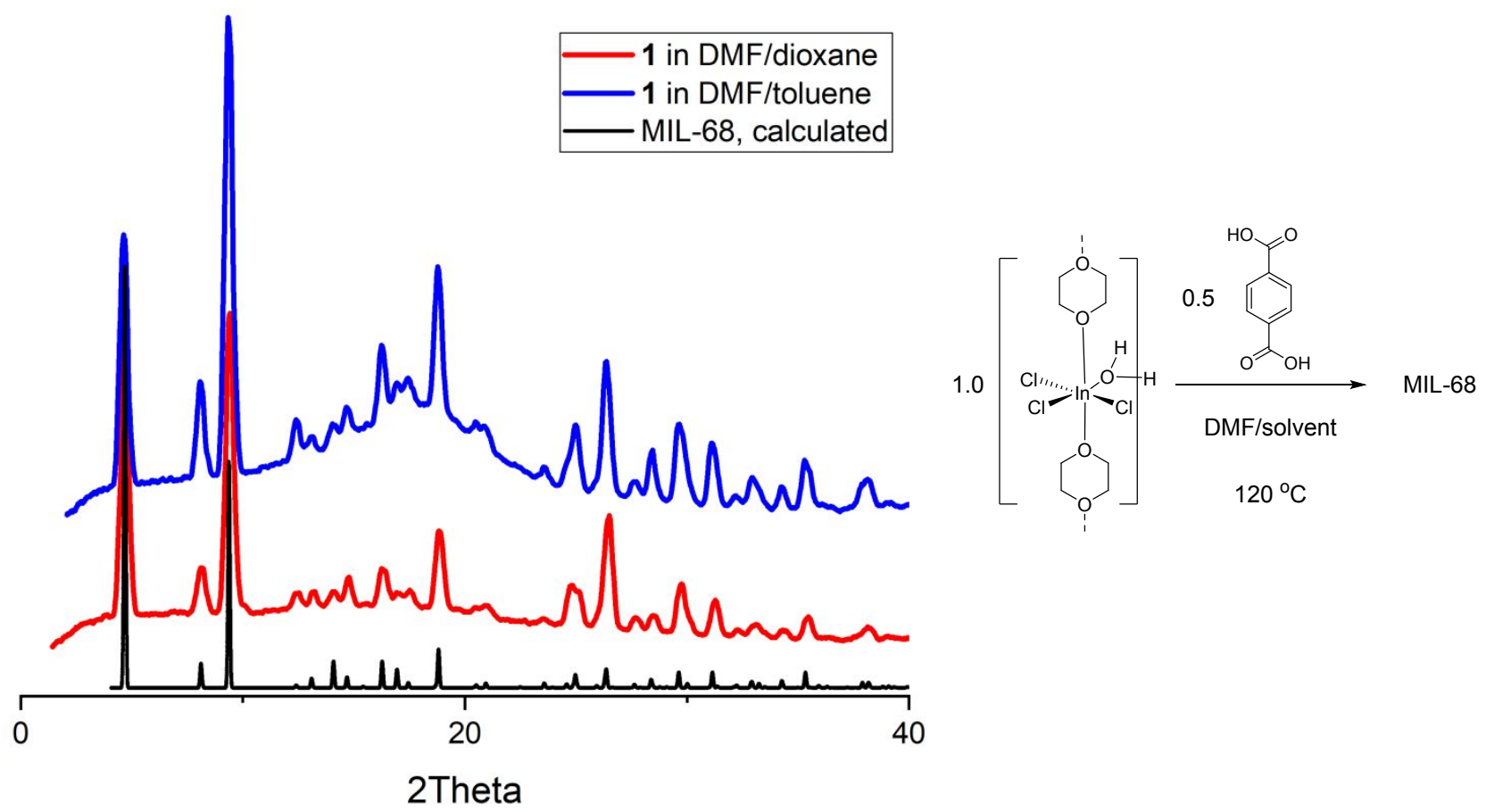

Figure S16. X-ray powder diffraction patterns of MIL-68 using different mixed solvent systems. Both traces were from reactions carried out at $120^{\circ} \mathrm{C}$. 


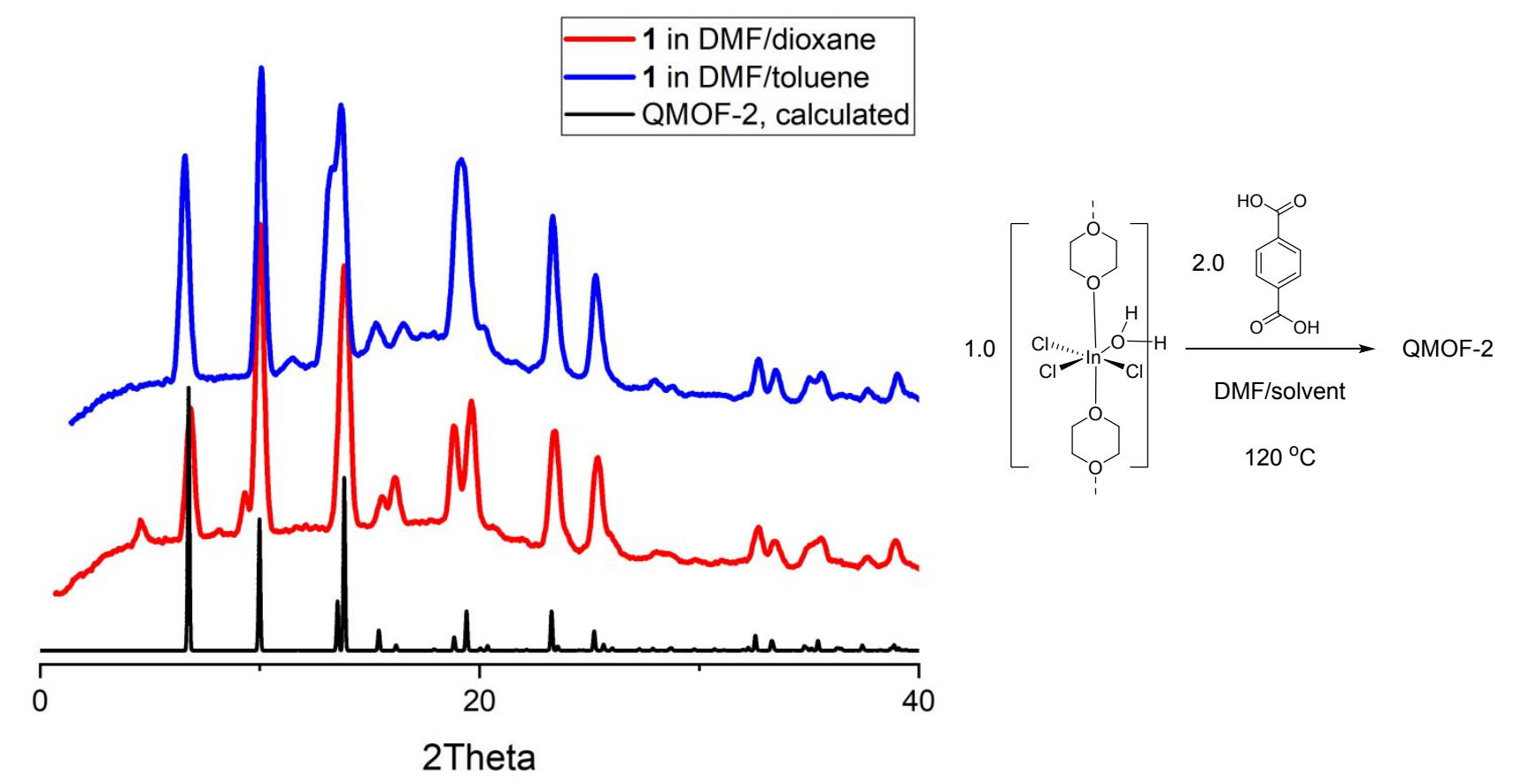

Figure S17. X-ray powder diffraction patterns of QMOF-2 using different mixed solvent systems. Both traces were from reactions carried out at $120^{\circ} \mathrm{C}$.

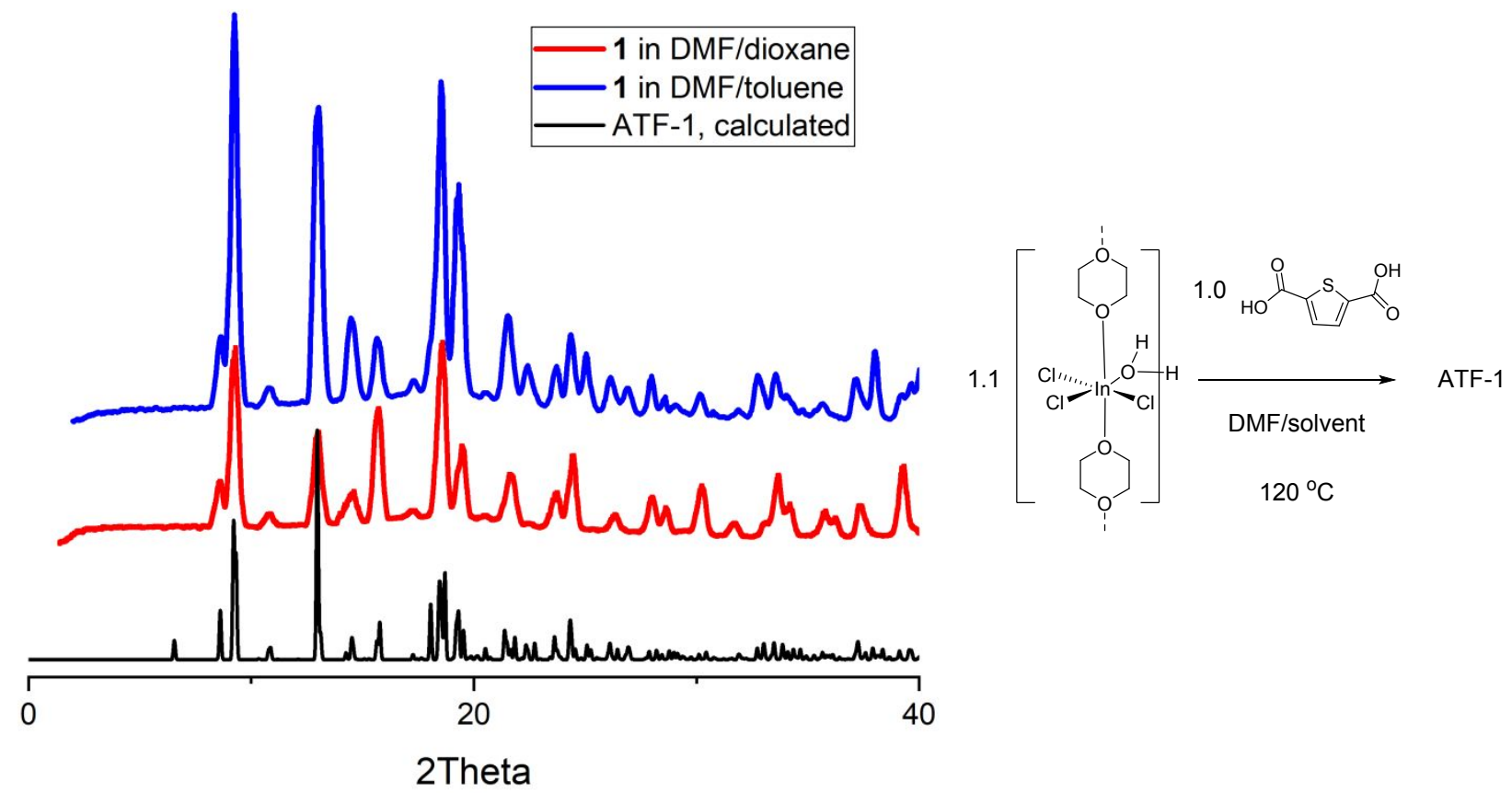

Figure S18. X-ray powder diffraction patters of ATF-1 using different mixed solvent systems. Both traces were from reactions carried out at $120^{\circ} \mathrm{C}$. 


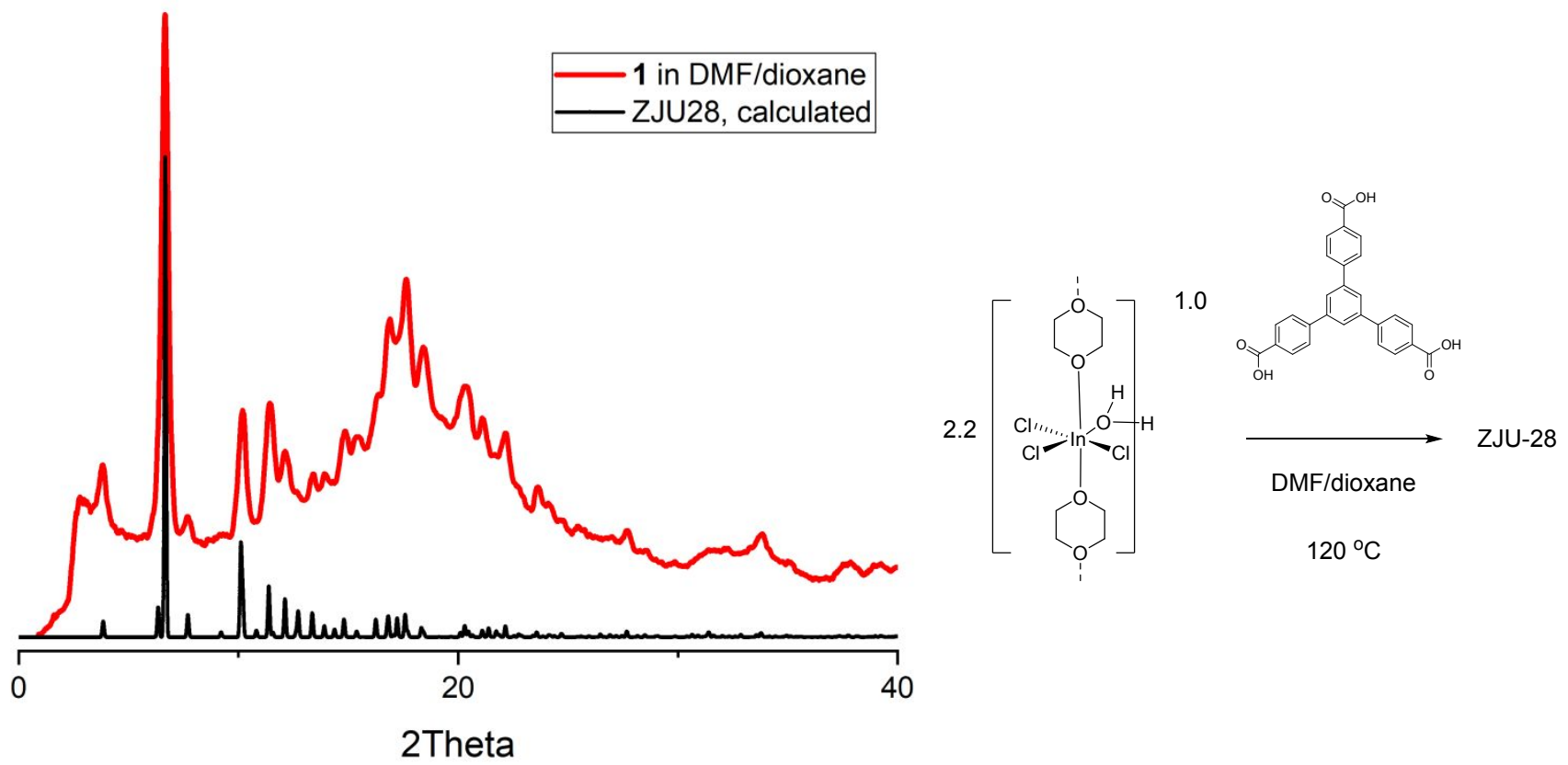

Figure S19. X-ray powder diffraction pattern of ZJU-28 in DMF/dioxane. Reaction carried out at $120^{\circ} \mathrm{C}$.

\section{Raman Data Collection}
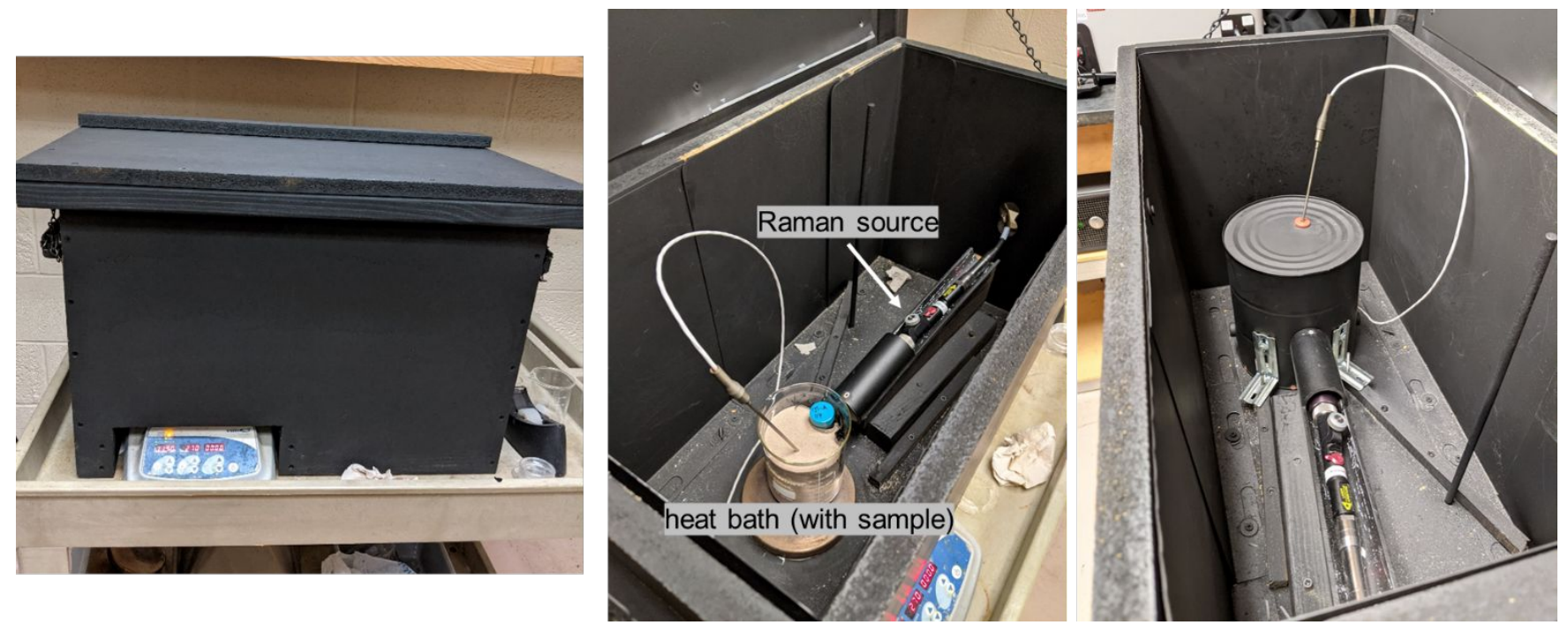

Figure S20. In-house Raman "oven"-like environment. Shown with closed box (left), use of sand bath for heating (middle), and with the metal covering in place (right). 
For all in situ Raman spectroscopy data collections: samples were prepared in $20 \mathrm{~mL}$ scintillation vials with Teflon-lined caps as $0.1 \mathrm{M}$ solutions. The solutions were neither sonicated nor filtered, as to not induce chemical transformations with the ultrasonication.

Vials were then placed into a sand bath, secured with electrical tape, and placed on top of a temperature controlled hot plate. A metal covering was placed over the entire hot plate creating an "oven" like environment. A temperature probe was inserted through a bored hole in the top of the metal covering. Once the heating element was turned on, experiments would take 45-60 min to equilibrate at the set temperature. Raman data was collected as soon as the heating element was turned on and new spectra were recorded every 2 minutes. Acquisitions consisted of 102 -second scans.

Data processing was performed using MatLab (version 2020a). Processing included normalizing the spectra to the solvent peaks, and then subtracting out the solvent. Copies of the code/script for this process are available upon request.

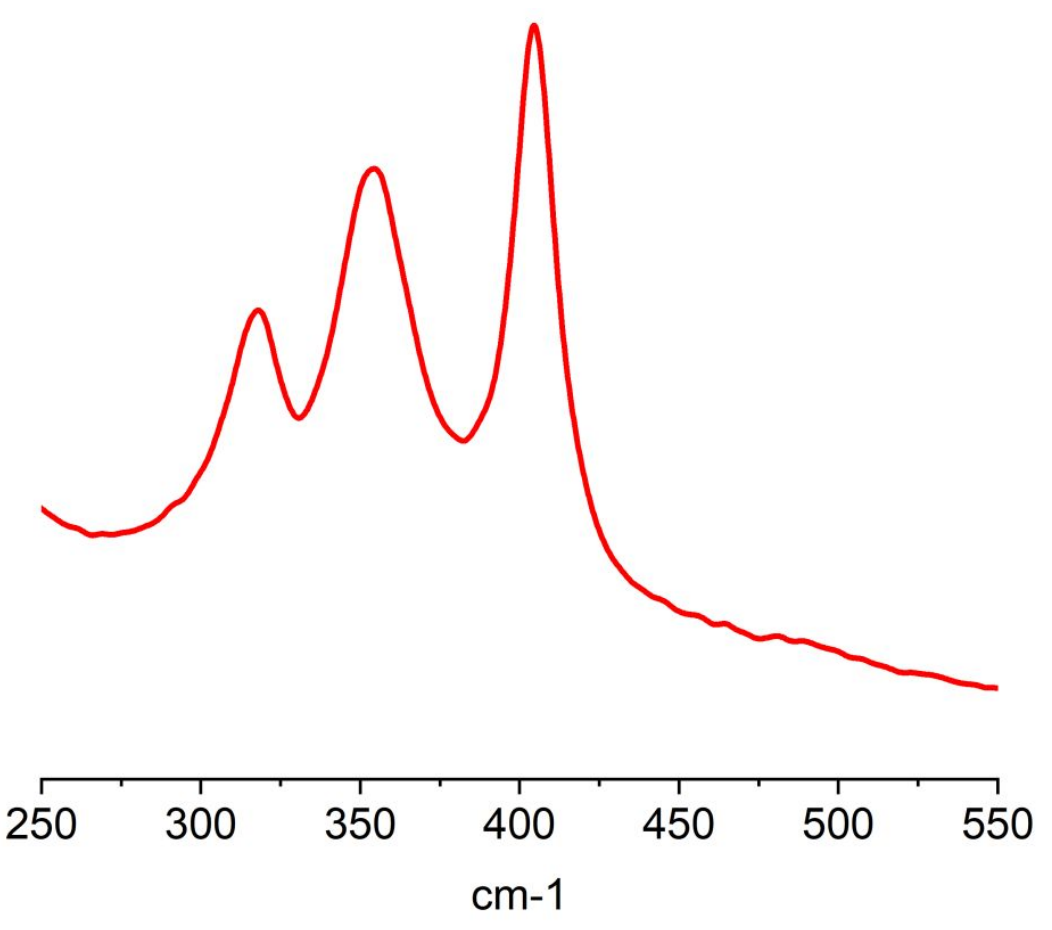

Figure S21. Raman spectrum of DMF at $65^{\circ} \mathrm{C}$. 

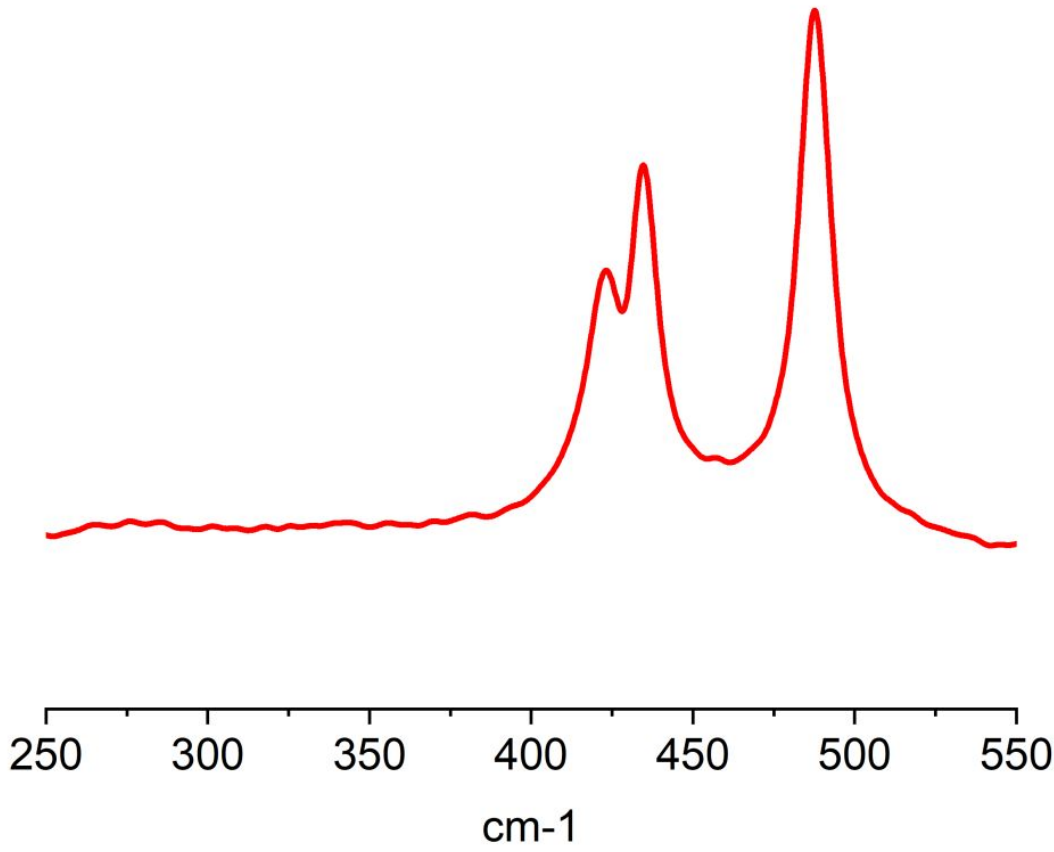

Figure S22. Raman spectrum of dioxane at $65^{\circ} \mathrm{C}$.

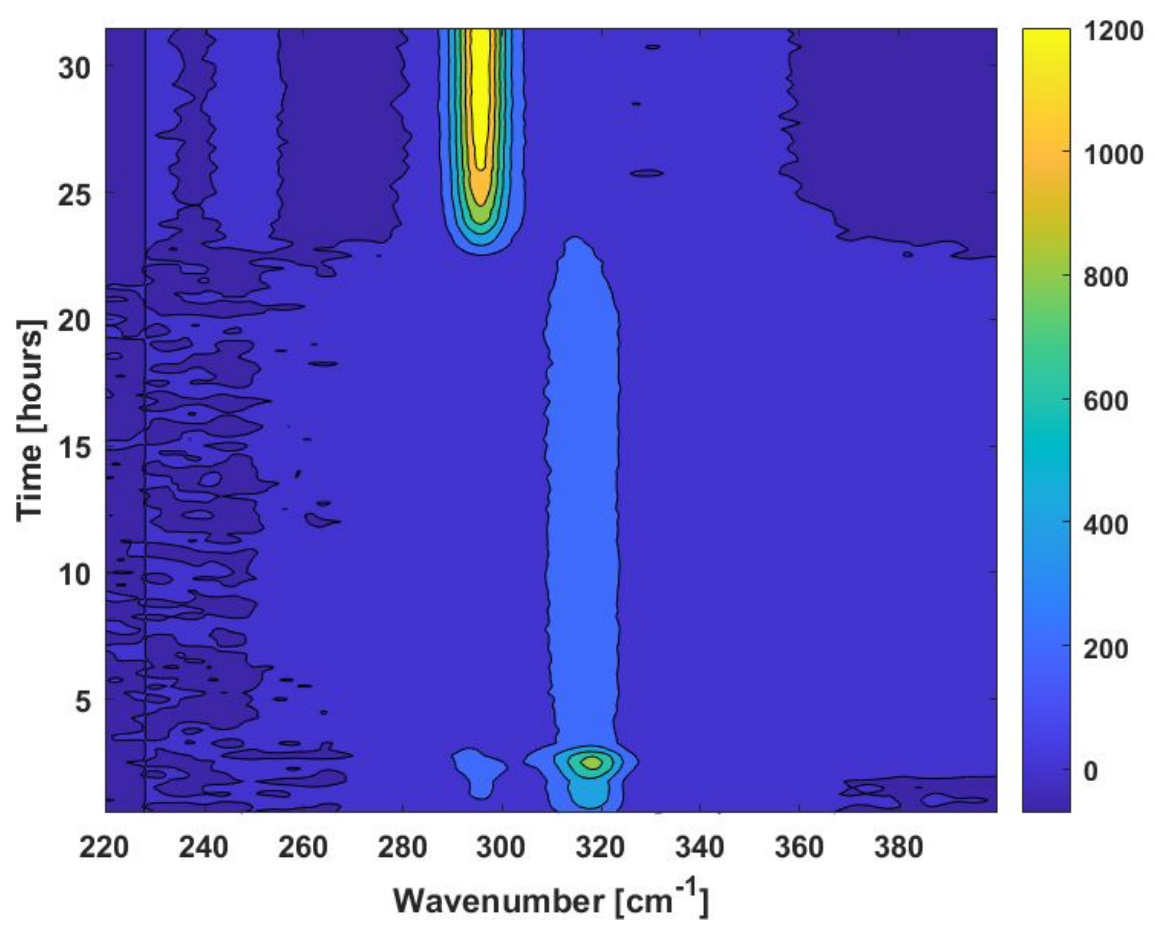

Figure S23. 2-Dimensional contour plot of Raman data of $\mathrm{InCl}_{3}\left(\mathrm{OH}_{2}\right)$ in dioxane heated at $65{ }^{\circ} \mathrm{C}$ for 22 hours and then cooled to room temperature. 


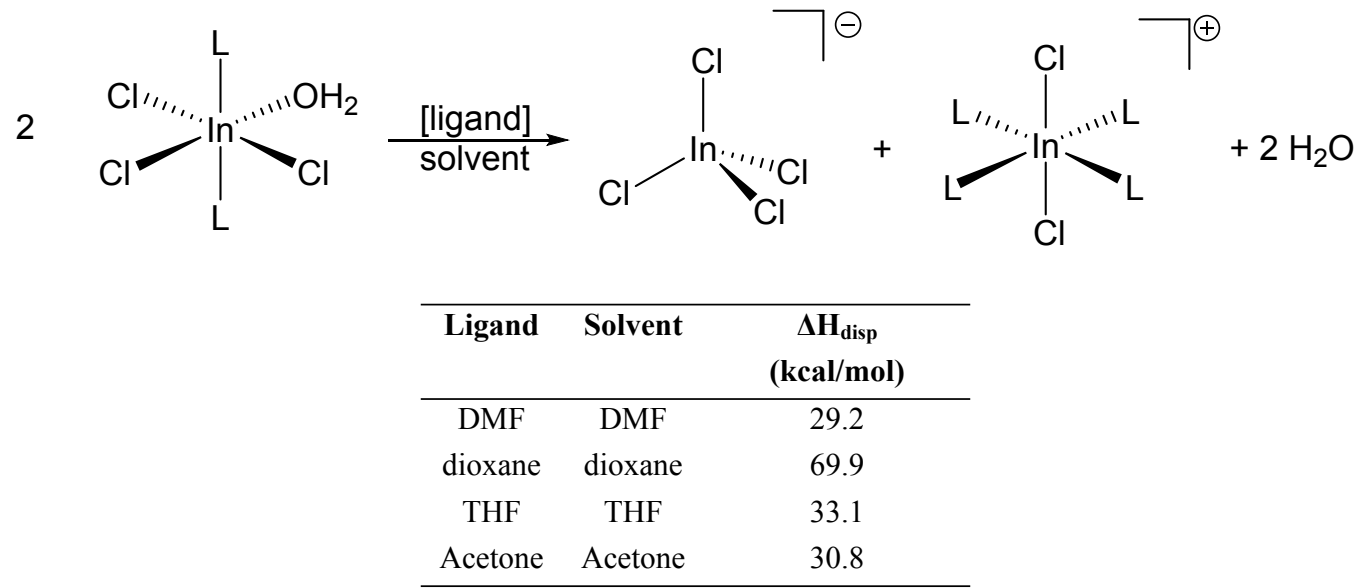

Table S2. Summary of computational data ( $\omega$ B97X-D functional and 6-316G basis set) for the disproportionation of octahedral $\mathrm{InCl}_{3}$ (trans-solv $)_{2}\left(\mathrm{OH}_{2}\right)$. 


\section{Molecular Dynamics Computations}

The system consisted of one formate ion and 100 solvent molecules. Simulation were run in pure DMF, pure dioxane, and 1:1 mole ratio DMF:dioxane using classical molecular dynamics (MD). Bond, angle, dihedral, and pair potentials, as well as charges, were described using the Optiomized Potentials for Liquid Simulations (OPLS) force field. ${ }^{6}$ The system was prepared by randomly placing the species in a simulation box such that the initial density was $1 \mathrm{~g} / \mathrm{ml} \mathrm{using}$ Packmol. ${ }^{7}$ The system was first equilibrated under NPT dynamics for $10 \mathrm{~ns}$, followed by $10 \mathrm{~ns}$ under NVT dynamics, using the software package LAMMPS. ${ }^{8}$ Finally, data was collected over an additional $10 \mathrm{~ns}$ of NVT dynamics.

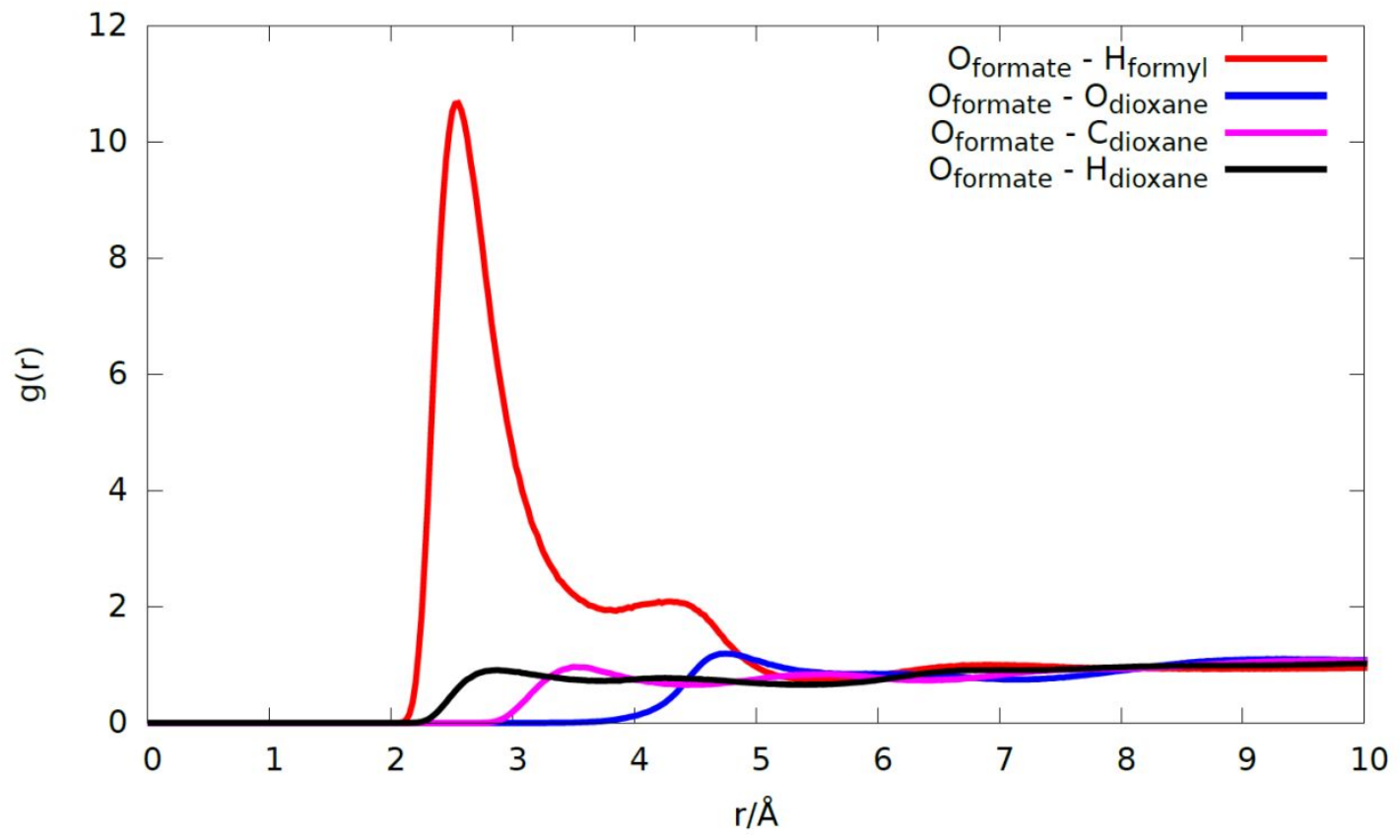

Figure S24. Radial distribution function (RDF) of formate oxygen to solvent.

The radial distribution function (RDF) between the formate oxygen with the formyl hydrogen on DMF and oxygen, carbon, and hydrogen is shown in Fig. S24. As shown in the RDF, solvation is dominated by the formyl hydrogen, and is at or near background even at short distances for all dioxane atoms. To better quantify the total solvation structure around formate, we tabulated the average number of solvate molecules around formate in our simulation. The minimum after the first solvation peak occurs at $3.8 \AA$, so we chose this as our cutoff distance for atoms solvating 
formate. At each step in the trajectory, a solvent molecule was considered to be solvating formate if any atom on the solvent molecule was within $3.8 \AA$ of any atom on formate. Using this criteria, we found that there were an average of 5.4 DMF molecules and 3.1 dioxane molecules with $3.8 \AA$ of formate. This suggests that dioxane does not sequester formate. 


\section{Single Crystal Structure Analysis}

Data were collected using a Bruker Quest CMOS diffractometer with Mo-Ka radiation ( $\lambda=$ $0.71073 \AA$ ) with an $\mathrm{I} \mu \mathrm{S}$ microsource and laterally graded multilayer (Goebel) mirrors for monochromatization. A single crystal was mounted on a Mitgen micromesh mount using a trace amount of mineral oil and cooled in situ to 110(2) K for data collection. Frames were collected, reflections were indexed and processed, and the structures were solved by direct methods using APEX $3 .{ }^{9}$ The space group was assigned using XPREP within the SHELXTL suite of programs ${ }^{10}$ and the structure was solved by direct methods using ShelXS ${ }^{10}$ and refined by full matrix least squares against $F^{2}$ with all reflections using Shelx $12018^{11}$ and the graphical interface Shelxle. ${ }^{12} \mathrm{H}$ atoms attached to carbon atoms were positioned geometrically and constrained to ride on their parent atoms, with carbon hydrogen bond distances of $0.99 \AA$ for aliphatic $\mathrm{CH}_{2}$ moieties. Water $\mathrm{H}$ atom positions were refined and $\mathrm{O}-\mathrm{H}$ and $\mathrm{H} \cdots \mathrm{H}$ distances were restrained to $0.84(2)$ and 1.36(2) $\AA$, respectively and further restrained based on hydrogen bonding considerations. $U_{\text {iso }}(H)$ values

were set to a multiple of $\mathrm{U}_{\text {eq }}(\mathrm{O} / \mathrm{C})$ with 1.5 for $\mathrm{OH}$ and 1.2 for $\mathrm{CH}_{2}$ units, respectively. Details of data collection, refinement and other special considerations are given in the below and in the Crystallographic Information Files. Complete crystallographic data, in CIF format, have been deposited in the Cambridge Crystallographic Data Centre (CCDC). CCDC \# 2091372 contains the supplementary crystallographic data for this paper. These data can be obtained free of charge from The Cambridge Crystallographic Data Centre via www.ccdc.cam.ac.uk/data request/cif. 
Local name: DTG_1_18B_b_0m

CCDC: 2091372

Table S3. Experimental details for $\mathbf{1}$.

\begin{tabular}{|c|c|}
\hline \multicolumn{2}{|l|}{ Crystal data } \\
\hline Chemical formula & $\mathrm{C}_{4} \mathrm{H}_{10} \mathrm{Cl}_{3} \mathrm{InO}_{3} \cdot \mathrm{C}_{4} \mathrm{H}_{8} \mathrm{O}_{2}$ \\
\hline$M_{\mathrm{r}}$ & 415.39 \\
\hline Crystal system, space group & Triclinic, $P \overline{1}$ \\
\hline Temperature (K) & 110 \\
\hline$a, b, c(\AA)$ & $6.9047(10), 7.8987(10), 14.360(2)$ \\
\hline$\alpha, \beta, \gamma\left({ }^{\circ}\right)$ & 85.997 (7), $87.541(7), 65.372(7)$ \\
\hline$V\left(\AA^{3}\right)$ & $710.10(17)$ \\
\hline$Z$ & 2 \\
\hline Radiation type & Mo $K \alpha$ \\
\hline$\mu\left(\mathrm{mm}^{-1}\right)$ & 2.23 \\
\hline Crystal size $(\mathrm{mm})$ & $0.26 \times 0.21 \times 0.08$ \\
\hline \multicolumn{2}{|l|}{ Data collection } \\
\hline Diffractometer & Bruker AXS D8 Quest CMOS diffractometer \\
\hline Absorption correction & Multi-scan, TWINABS ${ }^{13}$ \\
\hline$T_{\min }, T_{\max }$ & $0.561,0.746$ \\
\hline $\begin{array}{l}\text { No. of measured, independent and } \\
\text { observed }[I>2 \sigma(I)] \text { reflections }\end{array}$ & $46918,7233,6819$ \\
\hline$R_{\text {int }}$ & 0.111 \\
\hline$(\sin \theta / \lambda)_{\max }\left(\AA^{-1}\right)$ & 0.719 \\
\hline \multicolumn{2}{|l|}{ Refinement } \\
\hline$R\left[F^{2}>2 \sigma\left(F^{2}\right)\right], w R\left(F^{2}\right), S$ & $0.078,0.199,1.11$ \\
\hline No. of reflections & 7233 \\
\hline No. of parameters & 156 \\
\hline No. of restraints & 5 \\
\hline \multirow[t]{2}{*}{ H-atom treatment } & $\begin{array}{l}\mathrm{H} \text { atoms treated by a mixture of independent and } \\
\text { constrained refinement }\end{array}$ \\
\hline & $\begin{array}{l}w=1 /\left[\sigma^{2}\left(F_{\mathrm{o}}^{2}\right)+(0.030 P)^{2}+23.1713 P\right] \\
\text { where } P=\left(F_{\mathrm{o}}^{2}+2 F_{\mathrm{c}}^{2}\right) / 3\end{array}$ \\
\hline$\Delta \rho_{\max }, \Delta \rho_{\min }\left(\mathrm{e} \AA^{-3}\right)$ & $2.61,-2.51$ \\
\hline
\end{tabular}


Computer programs: Apex3 v2016.1-0, ${ }^{9}$ SAINT V8.37A, ${ }^{14}$ SHELXS97, ${ }^{10}$ SHELXL2018/3, ${ }^{15}$ SHELXLE Rev935. ${ }^{12}$

Refinement details: The crystal under investigation was found to be non-merohedrally twinned by two twin operations. The orientation matrices for the two components were identified using the program Cell_Now, ${ }^{16}$ with the second component being related to the first by a $180^{\circ}$ rotation around the reciprocal c-axis, and the third to the first by a $180^{\circ}$ rotation around the real a-axis. The three components were integrated using Saint and corrected for absorption using twinabs, ${ }^{13}$ resulting in the following statistics:

1873 data (608 unique) involve domain 1 only, mean I/sigma 33.8

1963 data (560 unique) involve domain 2 only, mean I/sigma 28.0

12428 data (2407 unique) involve domain 3 only, mean I/sigma 11.8

10852 data (2846 unique) involve 2 domains, mean I/sigma 31.2

20890 data (3243 unique) involve 3 domains, mean I/sigma 41.6

31 data (23 unique) involve 4 domains, mean I/sigma 38.2

3 data (3 unique) involve 5 domains, mean I/sigma 68.5

The exact twin matrices identified by the integration program were found to be:

$$
\begin{aligned}
& \text { Transforms h1.1(1)->h1.2(2) Transforms h1.1(1)->h1.3(3) } \\
& -0.99971-0.00054-0.00036 \quad 1.00047-0.00063-0.00196 \\
& 0.00080-1.00015-0.00113 \quad 0.95279-1.00006-0.00301
\end{aligned}
$$

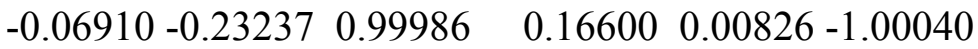

$$
\begin{array}{cc}
\text { Transforms h1.2(2)->h1.3(3) } \\
-1.00060 & 0.00171-0.00231 \\
-0.95211 & 1.00094-0.00222 \\
-0.09673 & 0.22421-1.00032
\end{array}
$$

The structure was solved using direct methods with the non-overlapping reflections of components 1 and 2 . The structure was refined using the hklf 5 routine with all reflections of component 1 and 2 (including the overlapping ones), resulting in BASF values of 0.321(2) and 0.173(3). 
The Rint value given is for all reflections and is based on agreement between observed single and composite intensities and those calculated from refined unique intensities and twin fractions (TWINABS). ${ }^{13}$

The ADP of the water oxygen atom was constrained to be the same as that of the chloride atom trans across the indium center. Water $\mathrm{H}$ atom positions were refined and $\mathrm{O}-\mathrm{H}$ and $\mathrm{H}$...H distances were restrained to $0.84(2)$ and 1.36(2) $\AA$, respectively. O...H hydrogen bonding distances were restrained to 1.92(2) Å. 


\section{References}

1. Apex2, Bruker AXS Inc: Madison, WI, 2003.

2. Mihaly, J. J.; Zeller, M.; Genna, D. T., Ion-Directed Synthesis of Indium-Derived 2,5Thiophenedicarboxylate Metal-Organic Frameworks: Tuning Framework Dimensionality. Cryst. Growth Des. 2016, 16, 1550-1558.

3. Volkringer, C.; Meddouri, M.; Loiseau, T.; Guillou, N.; Marrot, J.; Férey, G.; Haouas, M.; Taulelle, F.; Audebrand, N.; Latroche, M., The Kagomé Topology of the Gallium and Indium Metal-Organic Framework Types with a MIL-68 Structure: Synthesis, XRD, Solid-State NMR Characterizations, and Hydrogen Adsorption. Inorg Chem 2008, 47, 11892-11901.

4. Sun, J.; Weng, L.; Zhou, Y.; Chen, J.; Chen, Z.; Liu, Z.; Zhao, D., QMOF-1 and QMOF2: Three-Dimensional Metal-Organic Open Frameworks with a Quartzlike Topology. Angew Chem Int Ed 2002, 41, 4471-4473.

5. Genna, D. T.; Wong-Foy, A. G.; Matzger, A. J.; Sanford, M. S., Heterogenization of Homogeneous Catalysts in Metal-Organic Frameworks via Cation Exchange. J Am Chem Soc 2013, 135, 10586-10589.

6. Jorgensen, W. L.; Maxwell, D. S.; Tirado-Rives, J., Development and Testing of the OPLS All-Atom Force Field on Conformational Energetics and Properties of Organic Liquids. $\mathrm{J} \mathrm{Am}$ Chem Soc 1996, 118, 11225-11236.

7. Martínez, L.; Andrade, R.; Birgin, E. G.; Martínez, J. M., PACKMOL: A package for building initial configurations for molecular dynamics simulations. J Comput Chem 2009, 30, 2157-2164.

8. Plimpton, S., Fast Parallel Algorithms for Short-Range Molecular Dynamics. J Comput Phys 1995, 117, 1-19.

9. $\quad$ Apex3, Bruker AXS Inc: Madison, WI, 2016.

10. Sheldrick, G. M., A short history of SHELX. Acta Crystallogr A 2008, 64, 112-22.

11. Krause, L.; Herbst-Irmer, R.; Sheldrick, G. M.; Stalke, D., Comparison of silver and molybdenum microfocus X-ray sources for single-crystal structure determination. Journal of Applied Crystallography 2015, 48, 3-10.

12. Hübschle, C. B.; Sheldrick, G. M.; Dittrich, B., ShelXle: a Qt graphical user interface for SHELXL. J Appl Crystallogr 2011, 44, 1281-1284.

13. Sheldrick, G. M. TWINABS, 2012.

14. SAINT, V8.37A; Bruker AXS Inc.: Madison, WI, 2015.

15. Sheldrick, G. M., Crystal structure refinement with SHELXL. Acta Crystallogr C Struct Chem 2015, 71, 3-8.

16. Sheldrick, G. M. CELL_NOW, 2008/4; Universität Göttengen: Göttingen, Germany, 2008. 